\title{
A viewpoint on material and design considerations for oesophageal stents with extended lifetime
} \author{
Derek W. Edwards ${ }^{3}$, and Alison G. Harvey ${ }^{1, *}$ (D) \\ ${ }^{1}$ Department of Materials, University of Manchester, Manchester, UK \\ ${ }^{2}$ Dept. of Radiology, The Christie NHS Foundation Trust, Manchester, UK \\ ${ }^{3}$ Minnova Medical Foundation CIC, Wilmslow, UK
}

Caitlin E. Jackson ${ }^{1}$, Liam S. J. Johnson ${ }^{1}$, Dominic A. Williams ${ }^{1}$, Hans-Ulrich Laasch ${ }^{2,3}$,

Received: 22 October 2021

Accepted: 4 November 2021

Published online:

3 January 2022

(C) The Author(s) 2021

\begin{abstract}
Oesophageal stents are meshed tubular implants designed to maintain patency of the oesophageal lumen and attenuate the symptoms of oesophageal cancer. Oesophageal cancers account for one in twenty cancer diagnoses and can lead to dysphasia, malnutrition and the diminishment of patient quality of life (QOL). Self-expanding oesophageal stents are the most common approach to attenuate these symptoms. Recent advances in oncological therapy have enabled patient survival beyond the lifetime of current devices. This introduces new complications for palliation, driving the need for innovation in stent design. This review identifies the factors responsible for stent failure. It explores the challenges of enhancing the longevity of stent therapies and outlines solutions to improving clinical outcomes. Discussions focus on the role of stent materials, construction methods, and coatings upon device performance. We found three key stent enhancement strategies currently used; material surface treatments, anti-migratory modifications, and biodegradable skeletons. Furthermore, radioactive and drug eluting stent designs were identified as emerging novel treatments. In conclusion, the review offers an overview of remaining key challenges in oesophageal stent design and potential solutions. It is clear that further research is needed to improve the clinical outcome of stents and patient QOL.
\end{abstract}

$\begin{array}{llll} & & \text { BDS } & \text { Biodegradable stent } \\ \text { Abbreviations } & \text { CT } & \text { Computerised tomography } \\ \text { AC } & \text { Adenocarcinoma } & \text { DE-SEMS } & \text { Drug eluting self-expanding metal stent } \\ \text { AJCC } & \text { American Joint Committee on Cancer } & \text { DES } & \text { Drug eluting stent }\end{array}$

Handling Editor: C. Barry Carter.

Address correspondence to E-mail: alison.harvey@manchester.ac.uk 


\begin{tabular}{|c|c|}
\hline DTX & Docetaxel \\
\hline ePTFE & Expanded polytetrafluoroethylene \\
\hline $\mathrm{Fr}$ & French \\
\hline $\mathrm{I}-125$ & Iodine-125 \\
\hline MRI & Magnetic resonance imaging \\
\hline NiTiNOL & $\begin{array}{l}\text { Nickel-titanium navel ordinance } \\
\text { laboratory }\end{array}$ \\
\hline PCL & Polycaprolactone \\
\hline PE & Polyethylene \\
\hline PEG & Polyethylene glycol \\
\hline PIIID & $\begin{array}{l}\text { Plasma immersion ion implantation and } \\
\text { deposition }\end{array}$ \\
\hline PLGA & Poly(lactic-co-glycolic acid) \\
\hline PTFE & Polytetrafluoroethylene \\
\hline PU & Polyurethane \\
\hline SCC & Squamous cell carcinoma \\
\hline SEMS & Self-expanding metal stent \\
\hline SEPS & Self-expanding polymer stent \\
\hline
\end{tabular}

\section{Introduction}

Oesophageal stents are a necessary component of palliative care for patients enduring oesophageal cancers. They are implanted at the tumour's location using a thin tubular delivery system [1, 2]. Once positioned, the stent is expanded, bracing open the stricture of the mucosal walls of the oesophagus thus alleviating symptoms [1] (Fig. 1). Failure or migration of stents can lead to expensive repeat intervention and further stress upon already vulnerable patients.
The common incidence of failure of these stents therefore underpins this as a key area of biomaterials that requires research and innovation. We present here a review of the materials used in oesophageal stents and stent designs along with recent advances in the area.

Oesophageal cancer accounts for 5\% of all cancers worldwide with squamous cell carcinoma (SCC) and adenocarcinoma (AC) amongst the most predominant causes, the latter accounting for $60-70 \%$ of primary oesophageal tumours [3]. Cancers of either origin risk compromising the functional integrity of the oesophagus, notably its ability to transport food from the oral cavity to the stomach due to partial or full blockage of the tract [4]. Luminal occlusion is usually caused by tumour tissue growing concentrically in the oesophageal wall, which may occur anywhere along the length of the oesophagus. This reduces the functionality of the surrounding smooth muscle over time [4], instigating malignant dysphagia, a condition in which a patient is unable to swallow [5]. Dysphagia significantly impacts the quality of life of the patient, leaving the sufferer unable to enjoy eating or any social activities anchored to food [2]. Furthermore, unaddressed dysphagia has been linked to unhealthy patient weight loss and malnutrition, which itself has been identified as a major risk-factor for complications during chemotherapy [6].

Oesophageal cancer is characterised on a scale depending on the local extent of tumour growth, the presence of tumour deposits (metastases) in lymph nodes and other organs, as well as the severity of

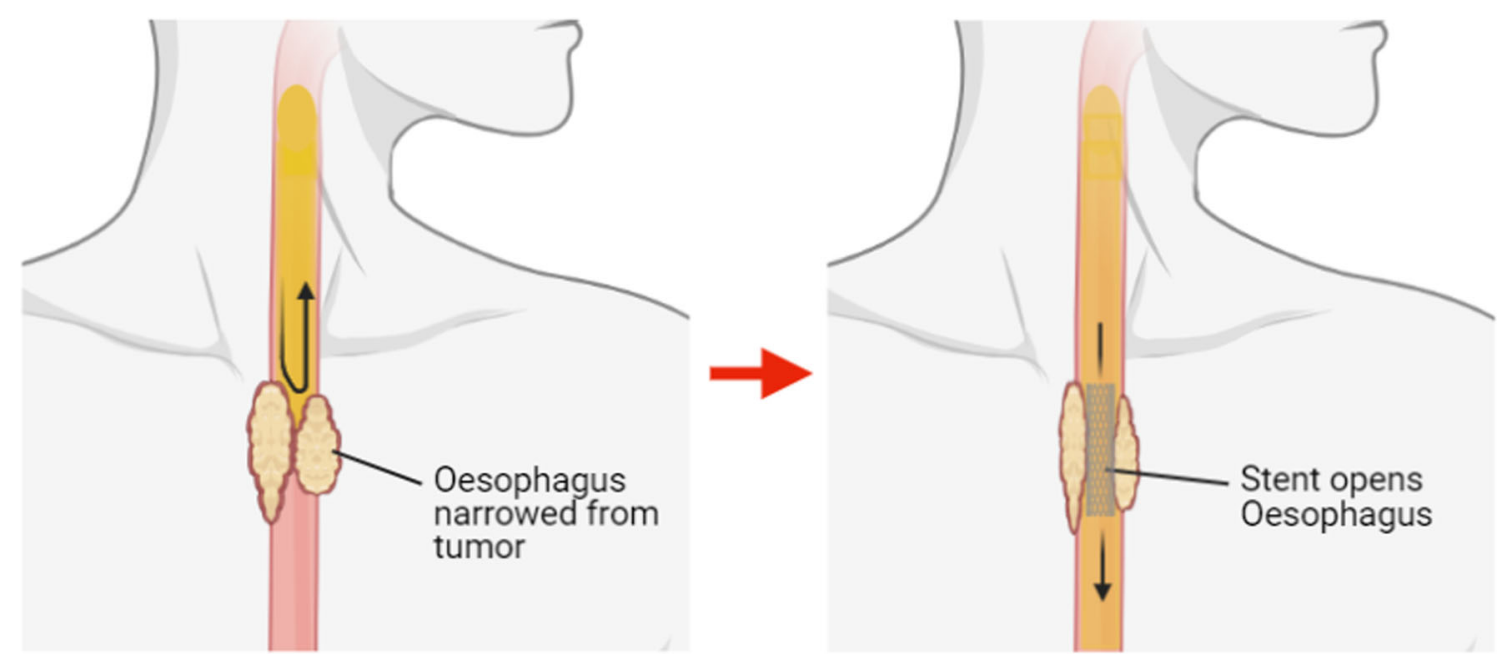

Figure 1 Schematic of oesophageal stent placement. Created with Biorender.com.

\section{Springer}


associated dysphagia [7]. The American Joint Committee on Cancer (AJCC) defines the parameters for ranking tumour progression based on its characteristic metastatic potential [7, 8], Table 1 . The most recent edition of this system collated data from 4,627 oesophagostomy patients, spanning across 13 institutions from 3 continents by the World Esophageal Cancer Collaboration [7, 9].

Within the AJCC's classification of oesophageal cancer is a subset category of the impact of dysphagia on the patient [10]. This secondary grading evaluates a patient from being able to eat a regular diet to complete blockage of the tract:

0: Normal diet possible.

I: Solid foods possible.

II: Semi-solids possible.

III: Liquids only.

IV: Total obstruction.

Many of the symptoms of oesophageal cancer manifest with a range of other conditions such as the common cold (cough and sore throat), achalasia (constriction of the gastro-oesophageal sphincter) and peptic ulceration [4]. As a result, the majority of oesophageal cancers are already at an advanced stage at diagnosis (Stage IV) [2], rendering the curative therapeutic approaches such as radical chemo-radiotherapy and surgical resection unviable. Furthermore, of those who do qualify for surgical resection, some $20 \%$ still experience post-operative dysphagia [11], from either post-operative anastomotic stricture, or tumour reoccurrence. As a result, many patients must consider palliative therapies to attenuate their dysphagia, for which self-expanding stents are the gold standard [12].

D'Etoilles' [13] first described a decalcified ivory stent in 1845 and since then both polymer and metal devices have found footing in the market. The development of oesophageal stents eventually gained traction in 1983 when E. Frimberger [14] inserted the first coiled metal stent, following work carried out by Zimmerman and King [15] fifteen years before whose coiled metal spring delivery was limited by the extent of luminal stricture. Frimberger's work instigated much of the interest surrounding coiled metal devices until the mid-1990s when Davids et al. [16] reported improved palliation via self-expanding metal stents (SEMS) versus self-expanding polymer stents (SEPS) for patients with malignant occlusions. Palma et al. [17] reported similar findings in a 1996 study which suggested that SEMS proved more favourable due to increased migration of polymer alternatives within the oesophagus.

There are currently approximately 35 stent designs in use in the UK health system [2], and stent longevity varies between 1 and 6 months in the literature [2, 18-20]. In the early 2000s, patient survival was typically 90 days following stent insertion and technical success was reported to be between 96 and $100 \%$ [21]. However, recent advances in oncology and developments in patient-specific medicine have dramatically lengthened patient survival time beyond 12 months [22], an example being the 24 country Trastuzumab trial, which found a combination of chemotherapy and antibodies for human epidermal growth factor receptor 2 (AKA Transtuzumab) to enhance median patient survival from 11.1 months to 13.8 months [23]. Consequently, lifetime of self-expanding stents has become inadequate, with now over $60 \%$ of patients experiencing stent failure within 6 months of insertion [2]. In one instance, Lunt et al. [24] described a 75-year-old female patient requiring four replacement NiTiNOL stents within a 20-month period to maintain feeding, due to repeated stent fracture. Similarly, Khara et al. [25] reported a 71-year-old female patient who developed candida esophagitis due to food impaction 7 months after stent placement, before full stent
Table 1 Classification of the advancement of oesophageal cancer set out by the American Joint Committee on Cancer, 2010 [8]

\begin{tabular}{lll}
\hline Status & Factor & Impact consideration \\
\hline $\mathrm{T}$ & Primary Tumour & - Extent of dysphagia \\
& & - Dimensions of tumour \\
& & - Affected structures \\
$\mathrm{N}$ & Regional Lymph Nodes & - Involvement of lymph nodes by metastases \\
& & - Dimensions of lymphatic metastases \\
$\mathrm{M}$ & Distant Metastasis & - Presence of distal metastatic growth \\
$\mathrm{G}$ & Histologic Grade & - Type and extent of cancer cell differentiation \\
\hline
\end{tabular}


fracture just 4 months later. This made the stent difficult to remove, as the proximal portion of the stent had embedded itself into the oesophageal wall, whilst the distal piece was wedged in the hiatal hernia.

Differences in stent manufacture, local healthcare purchasing policy, and supplier interests will influence price per stent. Consequently, the reported costs for oesophageal stents vary between clinics. For example, within the UK's National Health Service (NHS) SEMS are estimated to cost from $£ 600-£ 800$ (\$820-\$1090 USD) [26]. Whereas within China, the conventional self-expanding stents used are reported to cost just $¥ 2000$ (\$310 USD), with newer irradiated devices costing $¥ 4000$ (\$620 USD) [27]. Stenting therapy remains more affordable than alternative palliative therapies for dysphasia caused by oesophageal cancer, including LASER ablation, argon beam, and photodynamic therapy [28]. Therefore, within developing regions stent therapy is being implemented as a cost-effective and reliable strategy to treat oesophageal cancer. For instance, within Punjab (India) one study found over 95 of 100 patients in one rural hospital were able to get their stent therapy free of cost, due to a Government fund established to support cancer sufferers [28]. However, within many developing nations patients must fund treatment through out-of-pocket costs, limiting the accessibility of palliative stenting. In a 2021 analysis, Mushi et al. [29] explored how SEMS could be implemented to mitigate the high burden of oesophageal cancer in Eastern Africa, noting that devices should cost patients no more than \$100 USD to be affordable to a majority.

\section{Stent materials}

\section{Material considerations}

The materials used in stent design are key to the successful function and lifetime of the device [30]. This structural material must be biocompatible, have sufficient elasticity so as to be compressed for loading into the tubular delivery system and able to afflict sufficient radial force upon expansion to re-establish patency of the oesophageal lumen. Structural materials are categorised as either polymer or metal, Table 2.

\section{Polymer stents}

Prior to 1990 most oesophageal stents were manufactured from rigid polyvinyl plastic or rubber, which were proven to be successful in improving the occlusion for over $80 \%$ of patients [38]. However, common complications associated with this design include: stent migration, food impaction above the stent and perforation of the surrounding tissue for $\leq 10 \%$ of patients $[32,38]$. Additionally, the use of early polymer stents was dependent upon: the location of the tumour, the angulation and diameter of the oesophagus/occlusion at the insertion location and the condition of the surrounding tissue [30]. These restrictions often led to difficulty in insertion and increased procedural complication rates [39].

Two polymer stents currently commercially used within the oesophagus are: Polyflex (Boston Scientific) and SX Ella BD (Ella-CS). Polyflex was developed in 2003 and is a SEPS [40, 41], formed of a polyester mesh [32] (Fig. 2). SEPSs exert an outward radial force to allow self-expansion until the maximum diameter is reached. Several studies have demonstrated promising results from the use of Polyflex. In 2008, García-Cano [40] found that Polyflex proved to be easily extracted by grabbing the upper edge of the stent with endoscopic forceps, suggesting it is a useful device to treat benign gastrointestinal strictures. Langer et al. [42] demonstrated that Polyflex can be used in the treatment of oesophageal anastomotic leaks, successfully occluding the defect in 16 of the 18 patients using the SEPS. However, in both cases migration of the device proved to be an ongoing complication. Additionally, Holm et al. [43] observed that 18 out of $22(81.8 \%)$ Polyflex stents used to treat benign tumour occlusions migrated, particularly at the superior and inferior ends of the oesophagus.

SX Ella BD stents were developed in 2007 and were the first and are still the only commercially available self-expanding biodegradable stent [45]. They are woven from a monofilament of polydioxanone (Fig. 3), a semi-crystalline polyester [1,45]. They have shown clinical promise, with Sigounas et al. [46] reporting application in the treatment of both benign and malignant oesophageal tumours. The main complication was moderate retrosternal pain, most likely due to stent expansion exerting pressure onto the oesophagus. Sigounas et al. observed a mean patient lifetime of 19-98 weeks post-initial-insertion. 
Table 2 Current available metal and polymer oesophageal stents for the treatment of patients with malignant dysphagia

\begin{tabular}{|c|c|c|c|c|c|}
\hline Stent & Manufacturer & Material & Coated & Coatings & References \\
\hline \multicolumn{6}{|l|}{ Polymer } \\
\hline Polyflex & Boston Scientific & Polyester & Fully coated & Silicone & {$[30-32]$} \\
\hline SX Ella BD & Ella-CS & Polydioxanone & Not coated & N/A & {$[30]$} \\
\hline \multicolumn{6}{|l|}{ Metal } \\
\hline Gianturco Z & Cook Medical & Stainless Steel & Partially coated & $\mathrm{PE}$ & {$[31,32]$} \\
\hline WallFlex & Boston Scientific & NiTiNOL & Partially coated/ Fully coated & Silicone & {$[30-32]$} \\
\hline UltraFlex NG & Boston Scientific & NiTiNOL & Not/Partially coated & PU & {$[30-32]$} \\
\hline Bonastent & EndoChoice & NiTiNOL & Fully coated & Silicone & {$[30]$} \\
\hline FerX-Ella & Ella-CS & Stainless Steel & Fully coated & $\mathrm{PE}$ & {$[30-32]$} \\
\hline SX-Ella Flexella Plus & Ella-CS & NiTiNOL & Fully coated & Silicone & {$[30-32]$} \\
\hline EGIS & S\&G BioTech Inc & NiTiNOL & Fully coated & Silicone/ePTFE & {$[2,33]$} \\
\hline Alimaxx-ES & $\begin{array}{l}\text { Merit Medical } \\
\text { Endotek }\end{array}$ & NiTiNOL & Fully coated & PU/Silicone & {$[30-32]$} \\
\hline Hanaro & M.I. Tech & NiTiNOL & Partially coated/ Fully coated & Silicone & {$[33,34]$} \\
\hline NITI-S & $\begin{array}{l}\text { Taewoong Medical } \\
\text { Co }\end{array}$ & NiTiNOL & Partially coated/ Fully coated & Silicone (prev. PU) & {$[35,36]$} \\
\hline Niti-S double & $\begin{array}{l}\text { Taewoong Medical } \\
\text { Co }\end{array}$ & NiTiNOL & Partially coated/ Fully coated & Silicone & {$[30-32]$} \\
\hline $\begin{array}{l}\text { Niti-S Double anti- } \\
\text { reflux }\end{array}$ & $\begin{array}{l}\text { Taewoong Medical } \\
\text { Co }\end{array}$ & NiTiNOL & Fully coated & Silicone (prev. PU) & {$[30-32]$} \\
\hline Hilzo Hilzo ATM & $\mathrm{BCM}$ & NiTiNOL & $\begin{array}{l}\text { Partially coated / fully coated Fully } \\
\text { coated }\end{array}$ & $\begin{array}{l}\text { Silicone / Eptfe } \\
\text { Silicone }\end{array}$ & {$[37]$} \\
\hline
\end{tabular}

PE: Polyethylene; PU: Polyurethane; ePTFE: Expanded polytetrafluoroethylene; PTFE: Polytetrafluoroethylene

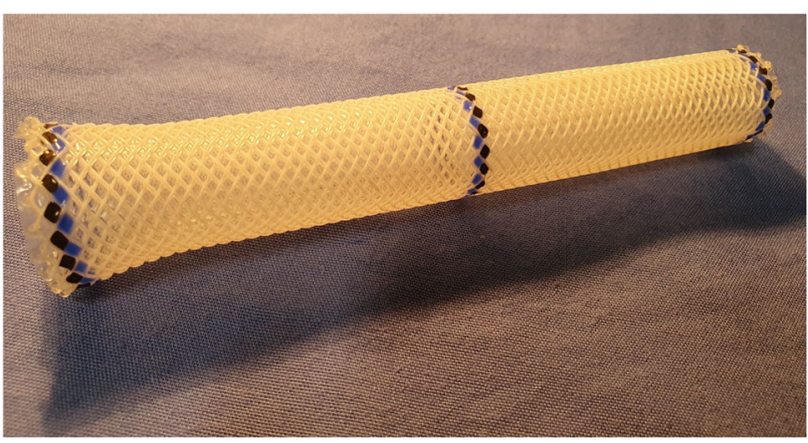

Figure 2 Polyflex stent fully expanded. The stent body inner diameter is $16-21 \mathrm{~mm}$ with a flare inner diameter of $20-25 \mathrm{~mm}$ and length $90-150 \mathrm{~mm}[44]$.

The polydioxanone stents increased the interval between oesophageal dilation interventions [47]. Oesophageal dilation is a practice to treat benign occlusions using a bougie or balloon. However, this carries a risk of perforation and patient death, although $50 \%$ of patients with malignant tumours required a replacement with a metal stent.

Advantages of non-biodegradable polymer stents compared to metal stents include: low cost and

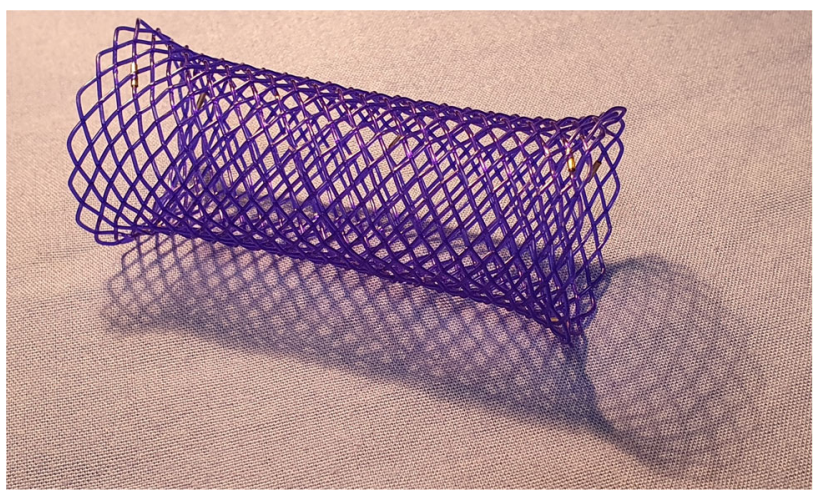

Figure 3 SX Ella BD stent, fully expanded. The stent body inner diameter is $18-25 \mathrm{~mm}$ with a flare inner diameter of $23-31 \mathrm{~mm}$ and length $60-135 \mathrm{~mm}$ [48].

limited local tissue reaction [30]. However, a major disadvantage of Polyflex and SX Ella BD, in addition to stent migration, is that both require manual loading and assembly of the delivery system before placement. A manual loading system comprises of a fully expanded stent which is manually compressed by the interventionist and inserted into a delivery 
tube. This requires larger delivery systems compared to similar metal stent systems, which are $28 \mathrm{Fr}$ $(9.3 \mathrm{~mm})$ for the Ella BD stent and up to $42 \mathrm{Fr}$ $(14 \mathrm{~mm})$ for the largest Polyflex, compared to a standard of $18 \mathrm{Fr}(6 \mathrm{~mm})$ for NiTiNOL stents for radiological placement and 10-11 $\mathrm{Fr}(3.3-3.7 \mathrm{~mm})$ for "through-the-scope" application [40, 41, 46].

\section{Metal stents}

In the early 1990s, SEMSs were introduced and since then have over taken SEPSs in the treatment of malignant tumour occlusions [31]. The two main metals used in SEMSs manufacture are: 316L stainless steel and NiTiNOL.

The elastic properties of stainless steel combined with its bio-resistance led to many clinical applications. The first generation of stainless steel stents was loaded into an applicator by the clinician immediately prior to insertion and released in situ. When released the device returns to its 'as-received' condition, relying on the elasticity of the alloy to reestablish luminal patency [31]. Z stents (Cook Endoscopy) are a group of stainless steel SEMSs, constructed in an interlocking ' $Z$ ' structure (Fig. 4), and the Gianturco-Z stent was the second SEMS developed [49]. In 1996, May et al. [50] observed them to have a lower rate of interventions when compared to similar stents commercially available at that time, WallFlex and UltraFlex (first and third commercially developed SEMS, respectively). This quality is desirable, and stainless steel seemed to be the most suitable material for SEMSs at the time. However, due to the rigid construction of its individual segments, the Gianturco-Z stent does not perform as well in curved or kinked occlusions, where it will not conform to the lumen or even cause pressure necrosis of the oesophageal wall [51], thus limiting the suitability of the stent to specific areas, such as the upper

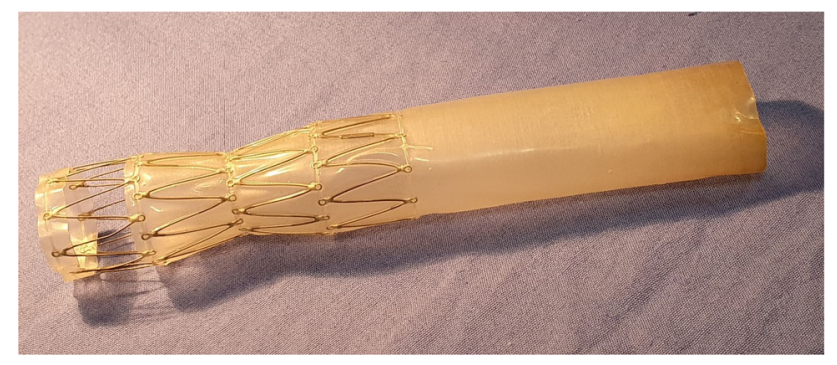

Figure 4 Gianturco-Z stent, fully expanded. Stent diameter ranges from 15 to $30 \mathrm{~mm}$ [53]. oesophagus [52], where the requirement of stent flexibility is reduced. The lack of flexibility in stainless steel stents led to the continued development of alternative SEMSs.

NiTiNOL is a nickel-titanium alloy capable of undergoing austenitic transformation from a deformed monoclinic (martensitic) phase to an ordered cubic (austenitic) phase across a given temperature range $[54,55]$. This shape-memory effect is initiated at a working temperature above that at which martensitic transformation occurs (Fig. 5). NiTiNOL stents are manufactured to specific dimensions, then annealed at $500{ }^{\circ} \mathrm{C}$, cooled and compressed and stored in a delivery system. Once implanted, the stent warms to body temperature which stimulates the expansion of the stent to the original dimensions [56, 57].

NiTiNOL stents are supplied pre-loaded in applicators, requiring no direct manual handling by the interventionist. This not only reduces the risk of infection but reduces the time a patient is under sedation or anaesthesia [18]. NiTiNOL has high fatigue resistance and ductility properties that make NiTiNOL advantageous for stents as they enable increased flexibility for obstructions in curved and kinked locations [52] and allow for repetitive muscle contractions during peristalsis.

Like many titanium alloys, NiTiNOL is biologically inert inducing acceptable in vitro and in vivo

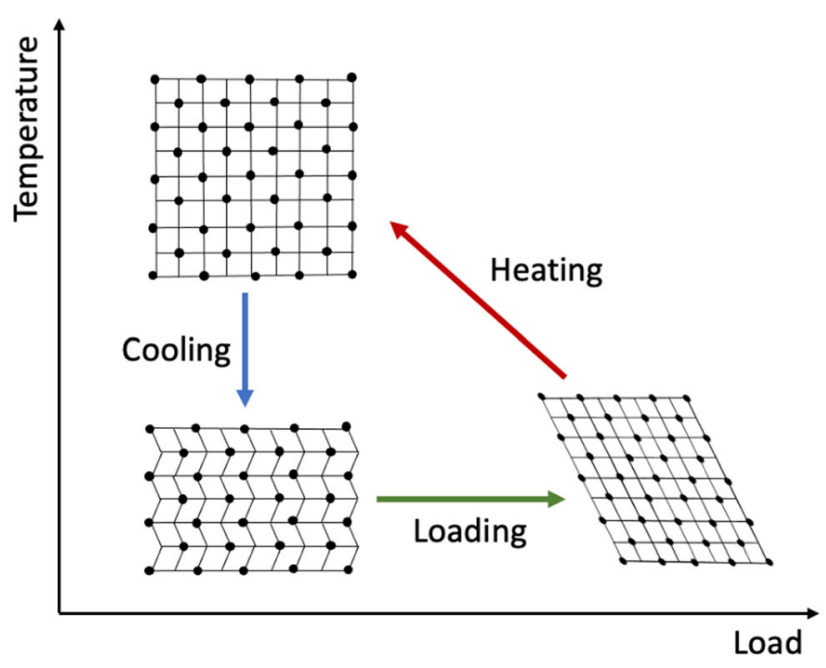

Figure 5 Martensitic transformation of cubic austenite to monoclinic martensite upon deformation of shape-memory NiTiNOL. Heating above the austenitic transformation temperature initiates austenitic transformation, revealing the original shape of the alloy. 
responses [57]. Furthermore through post-manufacture techniques, it enables formation of a defensive titanium (IV) oxide $\left(\mathrm{TiO}_{2}\right)$ film on the metal's surface, which prevents corrosion of the underlying skeleton $[57,58]$ and will self-heal, providing long-term protection [59]. This has been shown to promote cell interaction with minimal inflammatory or cytotoxic impacts on the surrounding tissue [60]. However, the oxide layer that forms on NiTiNOL naturally contains nickel $(\mathrm{Ni})$ ions, which have been linked to sensitisation of peri-prosthetic tissue [61] and carcinogenic effects when applied in high concentrations $[62,63]$. Furthermore, despite the protective influence of $\mathrm{TiO}_{2}$, persistent exposure to gastric acid in the lower oesophagus presents an extremely challenging environment [2]. As such, NiTiNOL devices regularly show evidence of corrosion-induced fracture within 6 months of implantation [1,24]. However, despite its important role in stent failure, corrosion-induced fracture of NiTiNOL SEMS remains understudied and until more data are collected, it is difficult to adjust current designs appropriately.

\section{Construction of stents}

\section{Coiled stents}

Stent flexibility, migration resistance, and accuracy are highly dependent on the device's construction method and design architecture. Therefore, manufacturers have been motivated to experiment with a wide range of shapes, coatings, and fabrication methods. One example popular in the 1980s was coiled, spring-like designs. A coiled stent is composed of singular thread of metal flat wire spiralled into a spring-like structure [64]. The first mention of a coiled stent is by Frimberger in 1983 [14], which was inserted endoscopically after being wound around the end of the scope and expanded to a diameter up to $39-45 \mathrm{Fr}(13-15) \mathrm{mm}$. The coil was reportedly held in place by the tumour tissue filling the spaces between the coiled wires. Frimberger observed that the coil migrated significantly, however provided no further comment on the impact on the patient. The insertion depended on the extent of stricture, but could penetrate through an opening with a minimum diameter of $9 \mathrm{~mm}$.

Frimberger's stent inspired the development of the EsophaCoil stent (Fig. 6), manufactured from

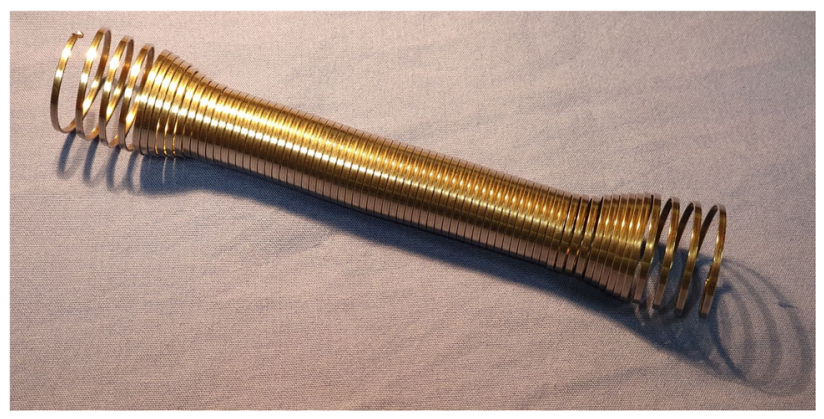

Figure 6 EsophaCoil stent, fully expanded. The stent diameter is $18 \mathrm{~mm}$ and stent length ranges from 75 to $160 \mathrm{~mm}$ [66].

NiTiNOL [65]. The EsophaCoil, developed by Goldin et al. [65], entered clinical trials $(n=4)$ in 1994. Similar to Frimberger's coil, the EsophaCoil was inserted via a $27 \mathrm{Fr}(9 \mathrm{~mm})$ introducing catheter. The coil was developed to overcome shortcomings in other stent designs, such as tumour ingrowth and tissue perforation due to little or no space between the coils and smooth edges, respectively. The coil succeeded in reducing tissue ingrowth throughout the trial, up to 11 months post-initial insertion; however, one patient required a replacement due to migration of the stent into the stomach after just 3 months [65]. Flared ends (Sect. 9.1) were introduced to overcome this issue with an immediate inhibition of migration reported. Nonetheless, it must be noted that only four patients were involved in the trial of these stents. Whilst the results are encouraging for both coiled stents and those with flared ends, further studies were not carried out to corroborate the results presented.

In comparison with other stents at the time, the EsophaCoil shortened the most (up to 50\%) and had the strongest, most rapid radial expansive force. Compression of stents into their delivery systems results in elongation, the degree of which depends on the stent construction, stent diameter and the degree of compression. The unavoidable shortening during release can lead to incorrect placement or early stent migration, and rapid expansion can increase retrosternal pain [15]. Furthermore, exposed wires at the ends of the coiled stents reportedly inflicted mucosal and muscular injury in patients due to perforation of the tract [15]. This was further aggravated by the increased stiffness of the device over stainless steel. 


\section{Laser-cut stents}

Laser-cut configurations are manufactured by using a focused pulsed laser beam to perforate a solid metal tube, leaving behind thin metal struts [1]. Laser-cut NiTiNOL stents are able to be mounted in a slim delivery system, 6-7 Fr (2-2.3 mm), allowing for easy insertion into patients with tight occlusions without dilation, reducing complications and procedure times [67].

Laser-cut stents have high radial expansive force $(1.65 \mathrm{~N} / \mathrm{cm})$ [68] and shorten the least during expansion $(<10 \%)$ allowing for accurate stent placement. Similar to coiled stents, the high radial force reduces the lateral compressive capability [1]. As a result, the stents do not conform well to curves, kinks and muscle contractions within the body. These stents tend to migrate, fracture or force the surrounding tissue to conform to the shape of the stent, leading to perforation of the tissue or necrosis due to high pressures exerted [1].

Ali et al. [69] presented an additional method of laser-cutting to produce a polyurethane stent comprised of carefully arranged squares with hinges at the point of contact between vertices. This design showed promise with its transverse expansion during elongation on insertion, a result of a negative Poisson's ratio [70]; however, there is little to be found on its in vivo efficacy. Although the crystallinity of the polyurethane could be altered to tailor the stiffness of the stent, the stiffness could restrict conformity to peristalsis and prevent nutrients and fluids from passing through the tract. This latter comment is speculative as Ali et al. provide no comparison of the polyurethane stent stiffness with current polymer and metal alternatives [15].

\section{Braided stents}

Braided stent configurations are manufactured by weaving a single strand of NiTiNOL around a mandrel resulting in a cross wire or S-weave structure [1] (Fig. 7a). Braided stents have a high radial expansive force whilst also retaining flexibility [71]. The wires are free to move across each other at their points of contact, allowing the stent to conform during muscle contractions in the oesophagus [33, 72]. However, when coated with silicone the movement of these wires is restricted, markedly increasing the axial rigidity of the stent. Due to the high axial force

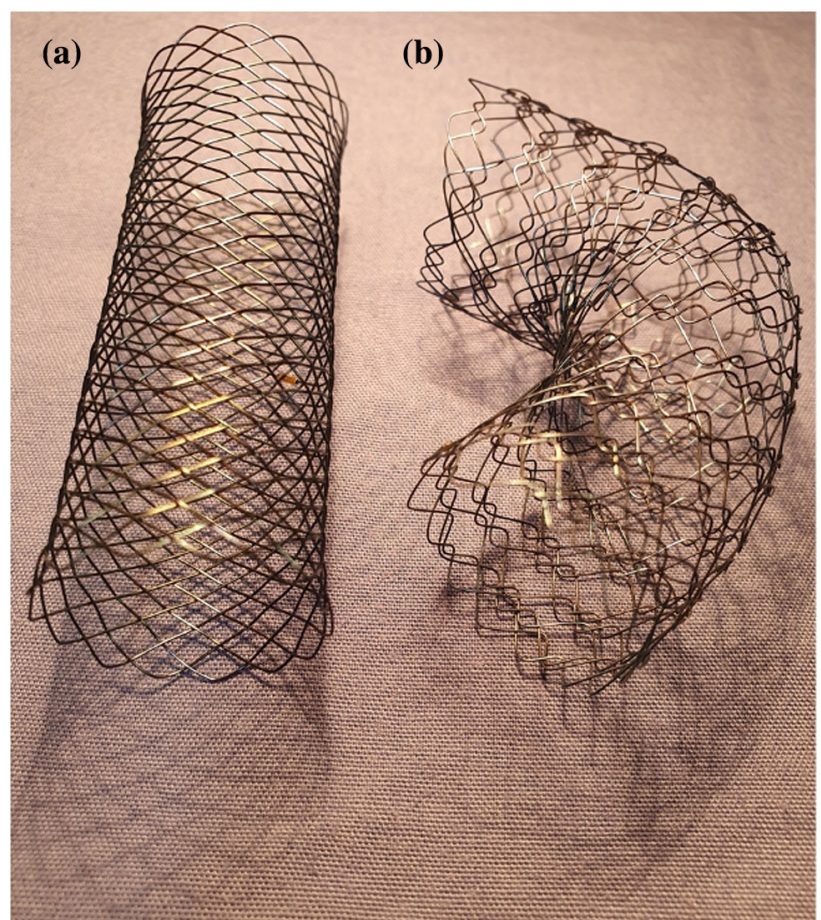

Figure 7 a Braided stents with wires in S-weave structure. b Knitted stent with wires looped around each other at right angles (D-weave).

resistance, braided devices are often slower to recover from axial loading which can cause disruption of the braiding pattern and of luminal patency. Constructing braided stents is highly labour-intensive primarily due to being handmade as no automated manufacturing method is yet available [73]. In addition, braided stents shorten significantly upon expansion (up to 50\%) which may lead to reduced placement accuracy of the stents. However, this challenge is overcome by having middle markers on the stent to ensure correct placement for full stent shortening [1] and continuously correcting stent position during deployment.

\section{Knitted stents}

Knitted stents are manufactured by bending a single strand of NiTiNOL around pins in a mandrel and looped around wire in other segments within the stent structure, forming a hooked wire or D-weave configuration [1]. Knitted stents can displace both laterally and longitudinally with high flexibility [72], and this results in a low axial force resistance, reducing the straightening forces of the stents to zero, thus enabling the device to stretch and contract 
during peristalsis with a low risk of foreshortening [33] (Fig. 7b). Foreshortening occurs when the device is unable to return to its original structure or shape easily and commonly leads to device contortion. This results in resistance against the peristaltic and flexural forces within the oesophagus, which can cause perforation of the muscle wall, mal-alignment and occlusion of the stent and stent migration [33]. The ability of knitted stents to conform to anatomical flexures increases the stents functionality and makes secondary intervention easier. This conformity has led to knitted stents becoming the most widely used stent construction [1]. Similar to braided stents, knitted stents are hand woven, making for labourintensive manufacture. However, the stent shortening upon expansion is reduced (up to 30\%) [1], improving placement accuracy compared to braided stents. Knitted stents are commonly covered by application of a membrane, either sewn onto the stent skeleton or sandwiched between two layers of NiTiNOL mesh. This leaves the wires still free to move and the cover does not alter stent mechanics.

\section{Metal vs polymer stents}

Biodegradable SEPS are still a popular choice as they do not require removal [74]. Conversely, nonbiodegradable SEPS have shown an increased risk of migration, potentially due to the reduced polymertissue interaction, which requires correction in secondary procedures [30]. Metal stents have shown superiority in this instance, initially because of hooks/barbs built into the design. Such features embed into the surrounding oesophageal tissue to prevent migration of the device over time, but also precluding removal. A 2008 survey of evidence by Yakoub et al. [75] evaluated 20 studies between 1990 and 2007, focusing on the efficacy of coated/noncoated SEMS $(n=1051)$ versus SEPS $(n=424)$ and their reasons for failure. Significantly less migration was observed for SEMS (2.1\%) compared with SEPS (13.1\%); however, they make no reasoning to the method of fixation. The Polyflex SEPS is of a very rigid construction and has only a gentle proximal flare. In addition to a large, bulky delivery system, the aforementioned characteristics pre-dispose displacement, as such Polyflex failed to take off commercially.
In contrast, uncoated SEMS have previously had more frequent complications regarding growth of tumour tissue through the meshwork and into the oesophageal lumen, affecting the passage of nutrients and fluids once again. Ramakrishnaiah et al. [76] reported a $52 \%$ failure rate of SEMS in patients $(n=42)$ predominantly due to tissue ingrowth compared with $32 \%$ for SEPS. Unlike SEPS, it generally is not possible to remove failed uncoated SEMS once tissue ingrowth has occurred due to increased risk of tissue damage. Yakoub et al. [75] reported tumour ingrowth of $13 \%$ in uncoated SEMS $(n=320)$, whilst SEPS $(n=487)$ exhibited a significantly lower $1.6 \%$. As a result, uncoated and partially coated SEMS are uncommon in practise.

SEMS and SEPS exhibit different peak radial and axial forces depending upon construction method and material choices [77]. The peak radial force is a measurement to indicate the outward expansive force of the stent, whereas the peak axial force is an indication of stent flexibility by measuring the straightening force exerted by the stent on the oesophageal wall when in a curved position [77]. Meike et al. [77] measured the peak radial and axial forces across 12 different stent designs and materials. The study found two distinct groups of stents, braided and nonbraided stents. There was comparable peak radial force across braided NiTiNOL and SX Ella BD stents $(<150 \mathrm{~N})$, whereas other non-braided metal and polymer stents exhibit a much higher peak radial force $(>300 \mathrm{~N})$. It is suggested this distinction is due to the braided configurations having the ability to elongate compared to the non-braided group which do not. Contrarily, the peak axial force was higher for braided NiTiNOL stents $(>1.5 \mathrm{~N})$ compared to nonbraided metal stents $(<1.5 \mathrm{~N})$. It is important to note that stent configuration is not the only variable to affect these forces with parameters such as: material stiffness, wire diameter and stent coatings, having additional affects [77]. For example, Polyflex has a configuration similar to braided stents; however, the polyester coating reduces the stents elongation potential [77], but consequently requires a larger delivery system.

In addition to the contrasting benefits and disadvantages found in the literature, the current general clinical outcome of both polymer and metal oesophageal stents varies. Kang [74] highlights the usefulness of polymer stents for benign tumours and metal designs for malignancies, whilst Yakoub et al. 
[75] suggest that little difference in function exists and that the primary concern now is cost-effectiveness. Amongst all reports, the biocompatibility of the device has not been questioned, supporting the use of both polymers and metals for the role. Determining a material based on the function required, location of use and availability is common practise in medical devices and so considering two different materials for benign versus malignant tumours may be of interest in the future.

Despite the occasional success in SEPS, the overarching consensus remains that SEMS outperform current plastic designs for palliative purposes, mainly because coated SEPS are difficult to load and deliver and frequently migrate from their site of expansion. This was demonstrated by Eickhoff et al. [78], who compared polyethylene type SEPS to Gianturco stainless steel SEMS. They found the polymer stents were equally good at relieving dysphagia, but resulted in considerably more complications (22\% vs. $9 \%$ in SEMS).

\section{Coated vs uncoated stents}

\section{Uncoated stents}

When first implanted in 1983 oesophageal stents were predominantly uncoated [14], allowing for good embedding into the tumour and surrounding oesophageal tissue, ensuring good anchorage at the site of the occlusion, thus reducing stent migration [2]. However, uncoated stents allow the growth of tissue through the gaps in the stent skeleton. Tissue ingrowth may be the result of proliferation of the surrounding tumour or severe hyperplasia (overgranulation) of the mucosal tissue in the oesophageal lining due to the trauma impacted upon the tissue when a stent embeds [79]. Uncoated SEMSs show the highest rates of tumour ingrowth, leading to repeat occlusion of the tract [20,30,74, 75]. In such circumstances the stent itself is irretrievable due to it being embedded in tumour tissue and manipulation carries the risks of injuring the already fragile surrounding muscle [18]. One solution here is to coat the stent with a protective polymer as investigated by Yakoub et al. [75]. For which, coated SEPS showed a lesser occurrence of tissue ingrowth $(1.6 \%, n=483)$, despite a higher frequency of stent migration (13.1\%, $n=483)$ than SEMS $(13.0 \%, n=32$ and $2.1 \%, n=320$, respectively).

\section{Coated stents}

Fully coated stents attempt to reduce the rate of tissue ingrowth in situ via a sheathing barrier surrounding the mesh implant. Subsequently, coated stents exhibit a reduced occurrence of tissue ingrowth, however with the trade-off an increased migration risk [74]. A variety of polymers have been used for stent coatings, including polyethylene, polyurethane and silicone amongst others [30] (Sect. 6). Each polymer is biocompatible for use in vivo and exhibits acceptable levels of interaction with the body. However, most commonly stent migration resulted in retrosternal pain, perforation of the oesophageal wall and in some cases patient morbidity [30, 31, 80]. Additionally, if the stent is coated by immersion in a liquid polymer, this reduces the flexibility and thus the conformability of the stents, further contributing to migration of the stents and the associated complications [72].

\section{Partially coated stents}

In light of increased tissue in-growth with uncoated stents, partially coated stents were designed to improve stent patency by providing a partial barrier against tissue ingrowth. Most commonly, partially coated stents have uncoated ends, with a polymer coating on the mid-section only [12, 32] (Fig. 8). In a study of partially and fully coated NiTiNOL stents, Boeckel et al. [20] highlight greater migration rates for fully coated stents (39\%) [36] than partially coated devices (6\%). Nevertheless, Schembre et al. [32] report that partially coated SEMS exhibit tissue ingrowth into the uncoated ends of the stent which subsequently inhibited easy retrieval of the device.

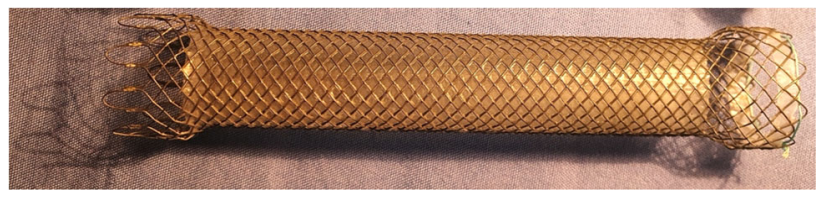

Figure 8 Partially covered braided WallFlex oesophageal stent incorporating dog bone shape to further increase stent anchorage. The stent body outer diameter is $18-23 \mathrm{~mm}$ with a flare outer diameter of 23-28 $\mathrm{mm}$ and length $100-150 \mathrm{~mm}$ with a covered length of $70-120 \mathrm{~mm}$ [81]. 


\section{Stent coatings}

\section{Silicone}

Silicone is a well-established bio-inert medical material which is typically used in catheters, contact lenses, augmentation implants (breast/testicular) and maxillofacial devices [82]. Silicone exhibits excellent flexibility [83] with both high tensile and compression recovery, allowing it to easily conform to surrounding forces without causing undue resistance and relax without creating tension. For oesophageal stents, silicone is primarily used as a coating material to prevent the ingrowth of cancerous tissue. Silicone itself is very hydrophobic [83], inhibiting the integration of peri-prosthetic tissue in situ. Therefore, silicone commonly undergoes surface functionalisation to increase hydrophilicity to promote cell adhesion [84] and to mitigate the risk of poor tissueimplant interaction induced failure [30, 80].

\section{Polyethylene}

Polyethylene (PE) was commonly used in the firstgeneration coated oesophageal stents, providing a bio-inert, hydrophobic material, resistant to in vivo degradation [85] and tumour ingrowth [12]. For instance, the Gianturco Z stent used a PE membrane to coat the stainless steel stent skeleton $[72,86]$, and more recently the FerX-Ella range by Ella-CS has employed PE coating to prevent tissue ingrowth through the mesh [12]. Additionally, David et al. [16] reported that a common failure mechanism for polyethylene $(n=56)$ related to the build-up of a paste-like substance; however, the chemical composition of this substance was not published in the literature.

\section{Polyurethane}

Due to the well-documented biocompatibility and non-toxic nature of polyurethane (PU), it is a common choice as the coating material for metal stents [30]. The relative stiffness of polyurethane is more easily tuned than that of polyethylene due to the presence of a 'soft' and 'hard' section within the polymer chain which can be altered to change the mechanical properties of the final product [69]. However, a study by Martinez et al. [31] $(n=42)$ revealed migration and food-blockage were key components in the failure of the device, generally more common with SEPS, despite observing a lower incidence of tissue ingrowth than with SEMS.

\section{Expanded polytetrafluoroethylene}

Since its discovery in 1983 [87], expanded polytetrafluoroethylene (ePTFE) has been used for a number of medical applications, including as a polymer coating for oesophageal stents. This material exhibits desirable properties, such as: biocompatibility, chemical stability, thermal stability and biological inertness [87, 88]. ePTFE is a soft, flexible, porous membrane that shares many of the properties of PTFE, such as biological inertness [89], providing ePTFE with the same 'non-stick' capabilities as silicone and providing protection from infection and local corrosion. ePTFE is the porous, expanded form of PTFE, and the interconnecting fibrils within ePTFE increase the strength of the polymer under pressure when compared to PTFE [85, 90].

\section{Surface-treatment techniques}

\section{Importance of post-treatment}

A variety of methods for processing NiTiNOL stents exist, focusing on the controlled growth of a passive oxide layer on the surface of the stent wire [60, 91-93]. Each technique has a specific set of parameters which determine the thickness of the resulting oxide. Such treatments include anodic oxidation, heat treatment and plasma treatment [91]. The thickness of this oxide layer determines the extent to which the body is able to interact with the device and the resulting response. Wang et al. [94] produced a titanium oxide thickness of 100-150 nm after $6 \mathrm{~h}$ of thermal oxidation at $450^{\circ} \mathrm{C}$ in an ambient air atmosphere, reporting significantly more bone formation within the oxide layer in rabbit models compared with 2- and 4-h oxidation protocols. Furthermore, Cigada et al. [95] reported that the corrosion resistance of titanium oxide layers to physiological environments is greatly enhanced above a thickness of $20 \mathrm{~nm}$. However, another study suggested little variation in efficacy against corrosion and promoting biological integration [96]. 


\section{Heat treatment}

Heat treatment is an inexpensive modification method, easily scaled up for incorporation into the stent manufacturing process [97]. Applied to titanium alloys, the treatment involves growth of a passive $\mathrm{TiO}_{2}$ layer, induced by exposure to gas ranging in temperature from 200 to $600{ }^{\circ} \mathrm{C}$ [92]. Along with temperature, oxide layer properties are dictated also by exposure time and air chemical constitution and alloy specimen, which will influence the thermal reaction between $\mathrm{O}_{2}$ and elements at the surface. This provides some control over oxide layer properties and allows for mitigated nickel ion formation in NiTiNOL, where $\mathrm{X}$-ray photon spectroscopy analysis has shown heat treatment using air at 500 and $600{ }^{\circ} \mathrm{C}$ will reduce surface nickel oxide [97]. However, control over this process is effected by the presence of undesirable oxidisable elements at the specimen surface and an abundance of oxidation agents in the surrounding air [92]. As such, secondary oxides may be unavoidable as part of the desired $\mathrm{TiO}_{2}$ layer, which may change the surface interactions of the material with the peri-prosthetic tissue [93].

\section{Plasma treatment}

Plasma treatment is a method of surface functionalisation, whereby a material's exterior is altered to enhance its response in specific environments, for instance the surface preparation of biomaterials to optimise their interactions with physiological components, such as proteins and cells [98]. Variations of plasma treatment include plasma polymerisation, plasma spray and plasma immersion ion implantation and deposition (PIIID), all being commonplace in biomaterial research and the electronics industry [93]. In particular, PIIID enables multiple surface functionalisation processes to be carried out together, such as the adsorption of particles and patterning of a design [93]. Additionally, PIIID may be modified so as to be effective for different materials like metals, ceramics and polymers. With this comes the ability to pattern 3D shapes into the surface of a specimen using a range of elements to form different functional islands [99]. Although these latter benefits pertain more so to PIIID, plasma spraying and plasma polymerisation share similar benefits in that they can functionalise the specimen surface with a wide range of chemistries to enhance hydrophilicity corrosion.
Plasma treatment has the capacity to selectively modify surface oxide thickness on an order of hundreds of nanometres [99] while not impacting the specimen's bulk composition [99]. For this reason, plasma treatment can be considered superior to other surface treatments such as anodic oxidation and heat treatments. Furthermore, plasma treatment is precise in its control over oxide layer composition. For instance, plasma treatment of NiTiNOL allows for minimal chamber pressures and oxygen concentrations, shown to mitigate formation of leachable nickel ions at the oxide layer [100]. This was exampled recently by Jenko et al. [60], who successfully induced a nickel-free oxide layer through application of radiofrequency inductively coupled plasma treatment. The experimenters achieved this by twice treating each sample in a custom reaction chamber, for $10 \mathrm{~s}$, at $600{ }^{\circ} \mathrm{C}$, with pumping speed at $80 \mathrm{~m}^{3} \mathrm{~h}^{-1}$ and pressure $0.3 \mathrm{mBar}$. In the first treatment, gas species $\mathrm{H}_{2}$ was used to induce a hydrogen reaction at the alloy's surface, eliminating the presence of nickel oxide. For the second treatment, all parameters were kept constant but gas species, switching to a mix of $\mathrm{H}_{2}(90 \%)$ and $\mathrm{O}_{2}$ (10\%). This encouraged rapid growth of $\mathrm{TiO}_{2}$ due to its low formation enthalpy, which in turn further suppressed migration of bulk nickel to the exterior, prohibiting nickel oxide formation. Finally the researchers characterised the material, finding that treated NiTiNOL exhibited reduced nickel ion leaching, enhanced fibroblast viability and superior corrosion resistance [60].

\section{Anodic oxidation}

Anodic oxidation utilises a voltage to induce the formation of a passive oxide layer [91]. The method is highly efficient and has been found to retain the original surface roughness whilst still producing a durable passive layer of uniform thickness [96]. This ensures that any surface features installed prior to passivation are retained as the surface porosity is built up [96, 101]. Compared with other methods, anodic oxidation is one of the simplest to implement and obtain results [91, 95, 96, 102]. Vera et al. [96] anodised Ti-6Al-4Y samples for $60 \mathrm{~s}$ at a range of voltages between 10 and $60 \mathrm{~V}(\mathrm{DC})$, to produce $\mathrm{TiO}_{2}$ layers ranging between 10 and $200 \mathrm{~nm}$.

However, anodic oxidation utilises an acidic solvent bath as part of the reaction. Therefore, during the oxidation process foreign oxides may form as a 
result of impurities in the acid or from the titanium specimen itself $[103,104]$. These foreign oxides within the $\mathrm{TiO}_{2}$ layer may not hold to the same biocompatibility and may even be cytotoxic to the surrounding tissue if implanted, posing a significant health risk to the patient [102].

\section{Stent failures}

To improve the lifetime of oesophageal stents, it is important to understand the failure mechanisms which the stents undergo. The common complications associated with oesophageal stents are: (i) stent migration or malposition, (ii) haemorrhage, (iii) food impaction and (iv) tissue ingrowth or overgrowth [105]. Complications generally result in pain and/or recurrent dysphagia (Fig. 9), both requiring further treatment for patients. Additionally, stress- and corrosion-induced fracture can be observed in stents that are implanted for a sustained period and can occur as early as 2 months post-insertion [2, 25]. Although this complication is currently less frequently observed, as patient survival times increase due to medical advances it is likely to become an increasingly common issue [25].

Factors such as tumour location, size, aggression and previous cancer treatment can affect the efficacy of oesophageal stents. It has been found that recurrent dysphagia in patients is more common in longer tumours $(\geq 10 \mathrm{~cm})$ than shorter tumours $(<10 \mathrm{~cm})$ (43\% and $17 \%$, respectively) [20]. Ideally stents should be long enough to extend over the occlusion

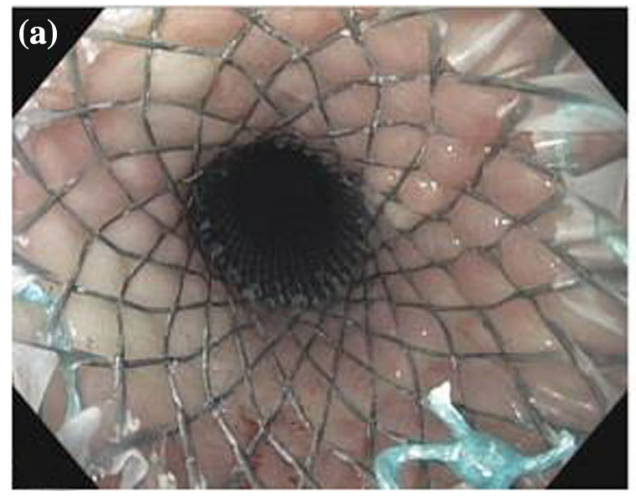

Figure 9 a Endoscopic view of a WallFlex stent following insertion. $\mathbf{b}$ Endoscopic view of a WallFlex stent with tissue ingrowth resulting in recurrent dysphagia. Reprinted from Gastrointestinal Endoscopy, 72/6, Petra G. van Boeckel, Peter D. Siersema, Richard Sturgess, Laura Dwyer, Isaac Raijman, Meike with an additional $2-4 \mathrm{~cm}$ at each end. Thus, an occlusion at either end of the oesophagus is difficult to stent. Complications are more common at these areas where stent placement is compromised [31].

Stents located lower in the oesophagus near the stomach are exposed to a more acidic environment due to the acidic gastric fluids. It is well documented that patients who require oesophageal stents suffer from gastroesophageal reflux [30] which causes a $\mathrm{pH}$ drop to below 4.0 [106] and, more importantly, predispose the patient to-potentially fatal-aspiration when lying down. Currently, stent manufacturers can voluntarily choose to use a corrosion test based on electrolytic corrosion tests for small implants (ASTM 2129) [107]. However, the ASTM 2129 corrosion test was originally designed for the testing of cardiac devices such as vascular and bile duct stents. The $\mathrm{pH}$ within the bloodstream is normally between the range of 7.37-7.43, similar to what is considered to be the normal oesophageal pH (7) [106], whereas the milieu in the bile duct is slightly alkaline in order to neutralise the low $\mathrm{pH}$ of the gastric content. Therefore, the ASTM 2129 does not provide a suitable platform to investigate the low $\mathrm{pH}$, chemically hostile environment in the oesophagus and conclusions concerning the durability of oesophageal SEMSs using this method may be unreliable. This lack of suitable corrosion testing could explain reports of stents prematurely disintegrating, as the acidic environment causes unanticipated local corrosion of the stent coating and/or stent skeleton.

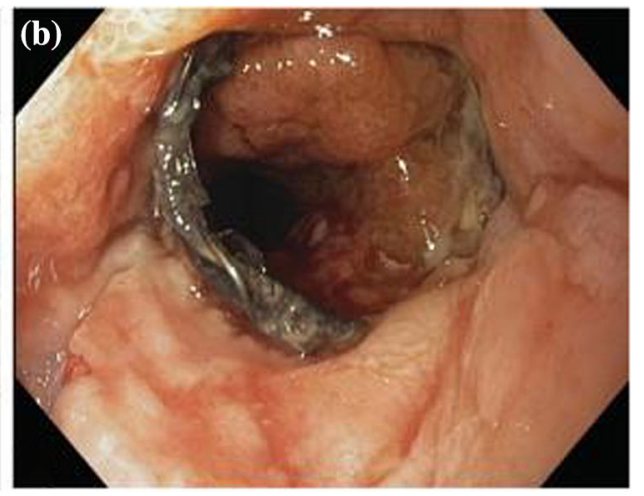

M. Hirdes, Frank P. Vleggaar. A new partially covered metal stent for palliation of malignant dysphagia: a prospective follow-up study, 1269-1273, Copyright (2010) with permission from Elsevier. 
In many cases currently, when tissue ingrowth or overgrowth or stent disintegration occurs, it is not possible to remove and replace the original stent. Therefore, a secondary stent is inserted over the original stent to restore patency, additional surgery can be required to retrieve migrated fragments [25]. Current stent lifetime is difficult to define, owing to wide variation in patient lifetime post-insertion (1-6 months) due to varying rates of tumour progression, unless a patient receives further palliative treatment [18-20, 108].

\section{Additional stent functions}

\section{Anti-migratory}

One of the most prominent early and late-stage complications observed across all stent materials and designs is migration, which is most common in fully covered stents. There are a variety of designs to combat stent migration, improving the anchorage capability of fully and partially covered stents whilst still providing a barrier to tissue ingrowth. Different designs incorporate different anchoring components, including: flared proximal and distal ends, hooks, double stents, anchoring flaps and pins [34, 45, 49, 109]. Pins, barbs and hooks improve stent anchorage by allowing the stent to physically bed in the tissue of the surrounding oesophageal wall.

Exampled in the commonly used first generation coated stent, Gianturco Z stent (Fig. 4) combines full stent coating with the addition of multiple anchoring components: flared proximal and distal ends and sharp central barbs/pins in the mid-section [49, 110]. However their effectiveness has been questioned in Bartelsman et al. [111], who observed that migration was still a significant factor with these stents, contributing to $14 \%$ of early and $9 \%$ of late reported complications. In addition, there was an increased risk of pain, oesophageal perforation and haemorrhage associated with the anchoring components [110]. Furthermore, these anchoring components increase the difficulty of removal and retrieval, thus increasing the risk of future complications $[30,110,111]$. In the event of migration or tissue integration with the device, there is often no other option, but to insert a second stent inside of the original to restore patency [1].
Alternatively, flared ends can be used without the addition of pins, barbs and hooks within a fully or partially coated stent. Use of flared ends reduces migration whilst also allowing for easier removal and retrieval of the stent if necessary [15]. Tomaselli et al. [34] conducted a study with UltraFlex stents (Boston Scientific), fully coated NiTiNOL stents with flared ends, to treat end stage malignant occlusions in the oesophagus, in which, only two patients out of 47 (4.3\%) developed late complications due to stent migration. Flared ends are a highly popular anti-migratory component incorporated into many SEMSs and SEPSs commercially available on the US and EU medical market [34].

SEMS, such as the Ella-HV (Ella-CS), use forward facing 'wings' in addition to flared ends (Fig. 10) at the proximal end of the stent providing improved anchorage [112]. Philbin et al. [113] reported the efficacy of Ella-HV stents compared to data from the registry of oesophageal stenting (ROST). The small study $(n=32)$ found $6.3 \%$ of Ella-HV stents migrated compared to $17.7 \%$ in ROST $2(n=615)$. In addition to reduced migration rates, grade 3 or 4 dysphagia in all patients $(n=10)$ with Ella-HV stents improved by at least 1 point, an improved result compared to patients in ROST 2 at 94\%. However, it was observed the Ella-HV delivery system, 28 Fr $(9.33 \mathrm{~mm})$, can require dilation pre-insertion for tight strictures.

Double stent designs, such as the double layered Niti-S oesophageal stent, have been developed to improve anchorage and reduce migration rates [86]. The Niti-S design incorporates an inner dog-boneshaped NiTiNOL stent covered in a polyurethane layer surrounded by an uncoated NiTiNOL mesh

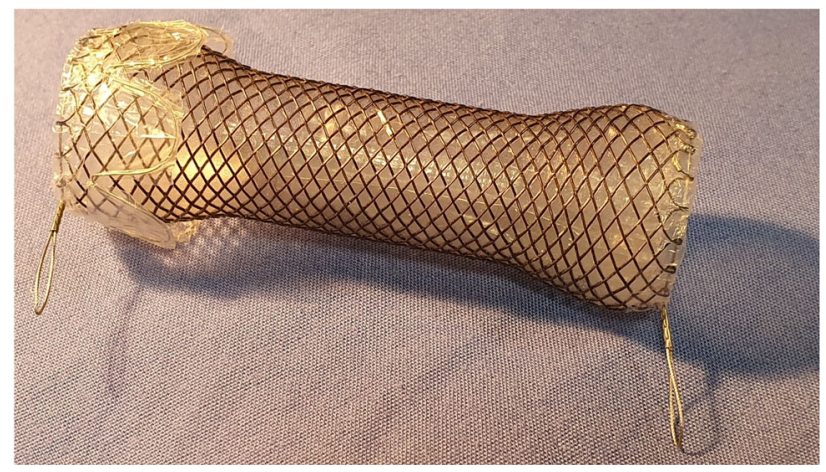

Figure 10 Ella-HV oesophageal stent demonstrating forward facing wings paired with flared ends to reduce the risk of stent migration. The stent body diameter is $18-20 \mathrm{~mm}$ with a flare outer diameter of $25 \mathrm{~mm}$ and length $85-150 \mathrm{~mm}$ [114]. 


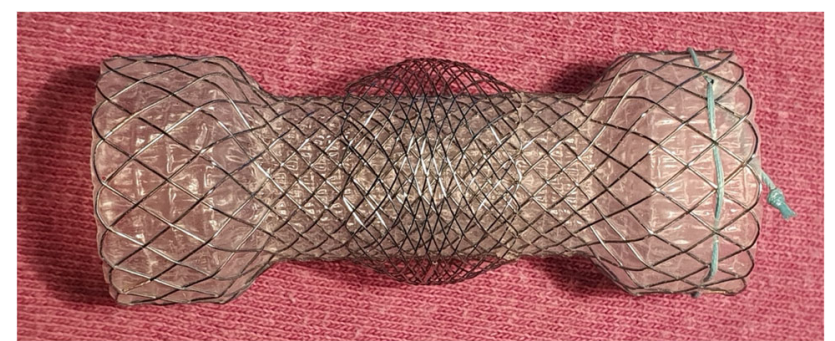

Figure 11 Niti-S double stent design demonstrating the inner dog-bone-shaped NiTiNOL stent covered in a polyurethane layer surrounded by an uncoated NiTiNOL mesh. The stent body diameter is $16-28 \mathrm{~mm}$ and stent length is $60-150 \mathrm{~mm}$ [115].

(Fig. 11) [35, 36]. The uncoated mesh allows tissue ingrowth to occur, thus improving anchorage and reducing the risk of stent migration. However, tissue ingrowth into the outer stent layer prevents the removal of the stent should any complications arise.

\section{Biodegradable}

Biodegradable stents (BDSs) are fabricated from biocompatible and biodegradable polymer materials [116], such as poly-L-lactic acid, polycaprolactone, polyglycolic acid, poly(lactic-co-glycolic acid) and polydioxanone [45, 116-119]. Their licensed use is only for benign stenoses of the oesophagus, as a dilation therapy where only temporary stenting is required [116]. This provides a less invasive treatment than repeated mechanical dilatations with a balloon or bougie. Research and development of BDS is more common in the cardiovascular stent market [117, 118, 120]. However, BDSs provide dysphagia relief and do not require removal, making them a relevant option for the treatment of benign and selected malignant oesophageal occlusions [121]. In the late 1990s, both Fry et al. [117] and Goldin et al. [118] reported small feasibility studies $(n=1$ and $n=6$, respectively) of the insertion of a poly-L-lactic acid coil BD-SEPS, which was designed to degrade via hydrolysis over 3-6 months. The results from the studies were inconsistent with only 2 out of the 6 patients having dysphagia relief past two months of the stent insertion. Tanaka et al. [122] further developed an 'UltraFlex-type' fabricated of poly-L-lactic acid in a knitted configuration. The study $(n=2)$ found the radial force of the stent to be comparable to other commercially available SEMSs with successful placement into the patient and dysphagia relief present at the 6-month follow-up appointment.
Furthermore, Liu et al. [119] observed the efficacy of poly(lactic-co-glycolic acid) (PLGA) biodegradable stents in rabbit models $(n=12)$. The stent composed of PLGA threads covering and connecting three curved sections of metal mesh. Once the PLGA degrades, the metal sections separate and drop into the stomach. 8 of the stents $(66 \%)$ degraded and moved into the stomach in weeks $6-8$ post-insertion. Overall, the PLGA covered metal stents retained strong radial force and biodegradable properties during the 8 week study.

The current (and only) BDS commercially available is the SX Ella BD (Sect. 2.2), a polydioxanone SEPS which gained regulatory approval by the EU in 2007 [45]. Polydioxanone degrades via hydrolysis of ester linkages which is accelerated by low $\mathrm{pH}$, leading to biodegradation within 11-12 weeks, and loss of mechanical strength past approximately 3 weeks $[1,122]$. However, the prosthesis still proved sufficient to improve patient symptoms for a median of 149.5 days (21 weeks), far surpassing the stent's lifespan [46]. Information from the manufacturer, Ella-CS, in unpublished studies reports the radial force remains consistent for up to 4 weeks with only a 50\% decrease by 9 weeks [123]. The initial degradation indications are material discolouration and minor fractures in the skeleton mesh at approximately 6 weeks with full stent degradation occurring between 11-12 weeks [123]. Pauli et al. [116] reported similar finding in a study using SX Ella BD in porcine models $(n=5)$. All animals in the study initially underwent endoscopic oesophageal mucosectomy (removal of the diseased mucosal tissue), and the effectiveness of immediate stent placement postprocedure in maintaining oesophageal patency was observed. There was little reduction in oesophageal diameter at 6 weeks with survival of the BDS group significantly longer than the non-stented control group, (9.2 weeks and 2.4 weeks, respectively). Conversely, however, Pauli et al. reported occlusion formation correlating with the degradation of BDSs, identifying challenges in maintaining patency in long-term applications.

Versus SEMS polymer BDSs do not require chemical cleaning and vacuum heat treatment [86]. BDSs offer lower patient care costs as they do not require removal. Furthermore, BDSs can also be used for drug eluting applications [124] (Sect. 9.3) and may better compliment current diagnostic techniques such as magnetic resonance imaging (MRI) and computer 
tomography (CT) due to the absence of metal artefacts which otherwise generate signal voids $[45,125]$.

\section{Drug eluting}

Drug eluting stents (DESs), including drug eluting self-expanding metal stents (DE-SEMSs), are designed with the aim to increase stent patency duration via incorporating anti-hyperplasia or antitumour functionalities [126]. DESs are formed of three components: a stent skeleton, a drug carrier and an active drug [127-130]. DESs have been widely researched for applications within the bile duct, but are not yet commercially available [130].

Several common active anti-cancer drugs such as paclitaxel, gemcitabine and 5-fluorouracil have been studied for drug eluting stents for the treatment of oesophageal and gastrointestinal cancers. These have been shown to inhibit cancer tissue proliferation and ulceration locally within the oesophageal tissue surrounding the stent, with minimal/no systemic or local toxic effects observed [131]. Liu et al. [131] developed NiTiNOL stents combined with a 50 $\mathrm{w} / \mathrm{w} \%$ paclitaxel or 5-fluorouracil layer within ethylene-vinyl acetate films demonstrating consistent and prolonged drug release (95 days). These stents exhibited the capability to inhibit proliferation of the surrounding tissue, maintaining oesophageal patency, and showed no significant negative systemic or local toxic effects.

Shaikh et al. [132] have designed a similar DESEMS using docetaxel (DTX) as the active drug component. The study found DTX-loaded medical gel (PurSil AL 20) formed a physically and chemically stable bilayer with sustained DTX release (> 30 days), whilst minimal permeation of DTX into oesophageal tissue in vitro was observed, displaying low toxicity. They additionally observed the permeation of DTX depended on the oesophageal tissue, further suggesting the sustained release of DTX may increase in vivo ( $>30$ days) [74].

Zhu et al. [133] developed a biodegradable electrospun drug-fibre-coated stent. The electrospun paclitaxel/polycaprolactone (PCL) fibres were collected directly onto a rotating stent. The study, which used canine models $(n=20)$, observed the DES was more effective than bare stents for treating benign occlusions within the distal end of the oesophagus close to the gastro-oesophageal junction.
However, many DESs lack unidirectional drug release to target the oesophageal mucosal tissue [74]. Therefore, drugs eluted from thin films can be released into the stomach via the interior of the stent. Lack of directed drug release can result in reduced drug delivery efficacy and increased side effects for the patient [74], such as nausea, vomiting and diarrhoea [134]. Guo et al. [130] developed a bi-layered stent coating comprising of 5-fluorouracil film and an ethylene-vinyl acetate drug-free backing. The study found high drug delivery efficacy into the oesophageal wall whilst successfully blocking the release of the drug through the interior of the stent. Lei et al. [135] similarly developed a multi-layered stent film coating comprising of PCL and polyethylene glycol (PEG) containing 5-fluorouracil and a backing layer to ensure unidirectional drug release. Similar to the bi-layer, the multi-layer configuration proved to be a successful polymer drug delivery system for localised, directional drug delivery.

Multi- or bi-layered drug delivery films provide improved control over directed drug release which may reduce side effects associated with anti-cancer drugs. Thus, this design of drug eluting stents provides the most potential for effective anti-hyperplasia and anti-tumour features. However, currently there is no drug-eluting stent for the oesophagus that is commercially available. Additionally, further development and evaluation through in vitro studies, and clinical trials, are still required to evaluate the efficacy and safety of active therapeutic agents eluted from such designs.

\section{Radioactive}

Radiotherapy is a common therapy in cancer treatment, with one of the oldest forms being brachytherapy [136]. Brachytherapy involves the use of a radioactive source placed close to a malignancy so the radiation damages and kills the tumour cells [136, 137]. Single-dose brachytherapy shows slower improvement compared to stents but results in better long-term outcomes for restoring patency with fewer associated problems, such as oesophageal perforation and haemorrhage. Consequently, brachytherapy has been recommended as a palliative treatment over the use of a stent to improve dysphagia.

Further research has combined stents, for immediate dysphagia relief, with brachytherapy, for improved long-term full patency [138]. Initial animal 
studies in rabbit models $(n=9)$ investigated attaching two plastic sheaths to the outer surface of the mid-section of a SEMS with both sheaths loaded with iodine-125 (I-125) seeds (Fig. 12). The I-125 seeds had a half-life of 59.6 days with a corresponding dose rate of $7.7 \mathrm{cGY} / \mathrm{h}$, irradiating across a $20 \mathrm{~mm}$ distance effectively. The animal study showed technical feasibility and relative safety, maintaining radio-tolerance in the surrounding tissue [139].

Further, human trials $(n=27)$ improved dysphagia grades and significant increase in survival of patients was observed in patients treated with I-125-loaded stents after 2 months compared to non-loaded stents. Later, Liu et al. [140] completed another human trial ( $n=31$ ) using the same I-125-loaded stents (Fig. 12) and showed similar findings. With improved dysphagia grades in the loaded stent group after 3 months. Additionally, the median survival of I-125loaded stent group increased versus the non-loaded stent group (4-month vs. 3-month). However, Liu et al. observed an increased incidence of oesophageal haemorrhages in patients with I-125-loaded stents versus non-loaded stents ( $35.3 \%$ vs. $21.9 \%)$. This is suggested to be associated with patient's previous radiation therapy history or a possible side effect of the high dosage rate of the I-125 seeds.

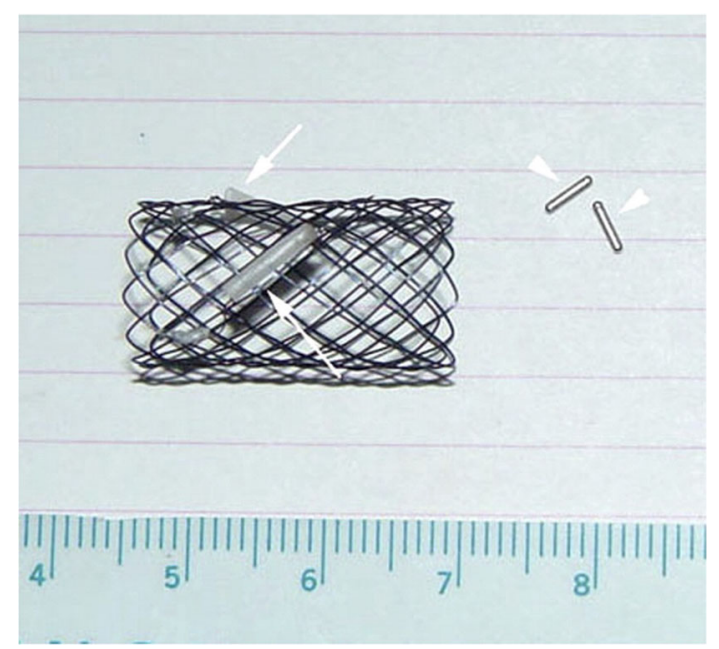

Figure 12 Bare NiTiNOL SEMS with attached plastic sheaths (arrows) loaded with I-125 seeds in cylinder alloy container (arrowheads). The stent is $10 \mathrm{~mm}$ in diameter and $15 \mathrm{~mm}$ in length. Reprinted from European Journal of Radiology, 61/2, JinHe Guo, Gao-Jun Teng, Guang-Yu Zhu, Shi-Cheng He, Gang Deng, Jie He, self-expandable stent loaded with 125I seeds: Feasibility and safety in a rabbit model, 356-361, Copyright (2007) with permission from Elsevier.
Although initial results for radioactive SEMSs are promising, further research is required as current sample sizes are too small to fully ensure feasibility and safety [139, 141], as demonstrated by Liu et al. [140]. Larger-scale clinical trials are required before radioactive stents become commercially available.

\section{Anti-reflux}

Whilst SEMSs restore patency in the oesophagus, the stents are susceptible to damage due to gastroesophageal reflux [51], most commonly seen in the distal region of the oesophagus, when the stent is placed across the gastro-oesophageal junction [142, 143]. Reflux causes an acidic environment $(<\mathrm{pH} 4.0)$ within the oesophagus [106], experienced as "heartburn", which can further cause damage to the stent skeleton via degradation and disintegration of the structural material [144]. This results in recurrent dysphagia and may further lead to tissue perforation from sharp edges. Furthermore, Coron et al. [145] found a clear objective, as well as symptomatic benefit, albeit at an increased rate of minor complications with anti-reflux stents versus conventional stents. A common misconception is heartburn can be treated as reliably with additional antacid medication; however, reducing the $\mathrm{pH}$ of the regurgitated gastric content does not reduce the risk of frank aspiration of fluid regurgitated in a supine position, which may be fatal [51].

Anti-reflux stents are designed with a one-way valve located at the distal end (Fig. 13). Initial investigations showed promising results and proof of concept with effective restoration of patency whilst additionally reducing damage due to acid reflux [145]. Laasch et al. [51] compared the effectiveness of open and anti-reflux stents. The study $(n=25)$ found $96 \%$ of patients with open stents had symptoms of oesophageal reflux compared to only $12 \%$ for patients with anti-reflux stents. Although having a significant impact on the reduction of oesophageal reflux, there was no significant difference in survival or complications for the patients. Furthermore, anti-reflux SEMSs designed for greater resistance to reflux can compromise the patency of the stent [145], and the design of anti-reflux stents may need further improvement. 


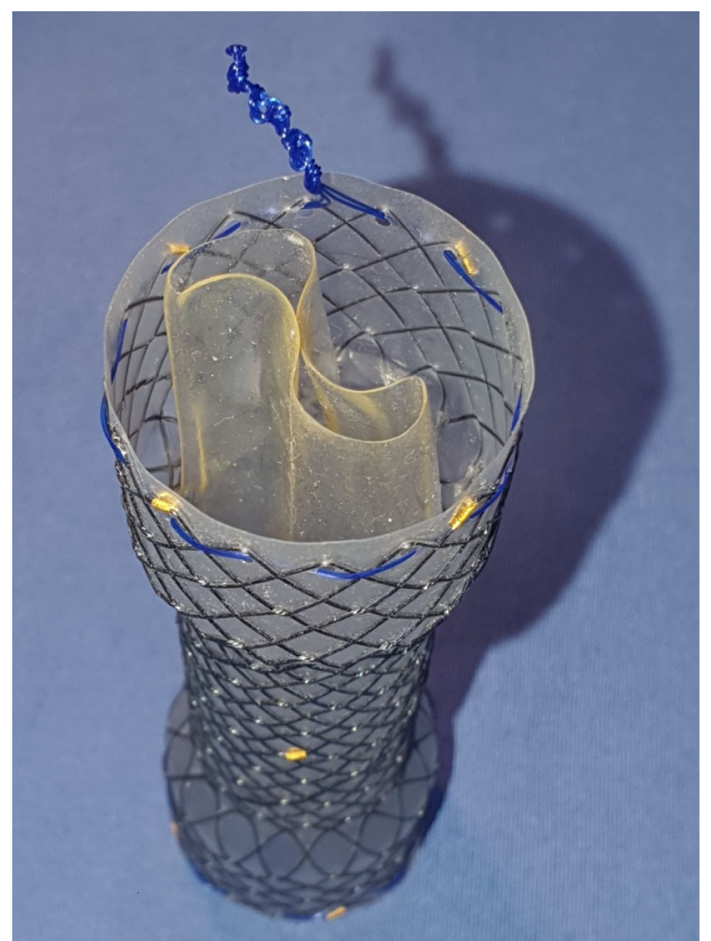

Figure 13 Anti-reflux stent, fully expanded, demonstrating the one-way valve, in this case located within the distal end of the stent.

\section{Future challenges and conclusions}

Despite the advances made since the work of D'Etoilles [13] and Frimberger [14], incorporating a range of structural stent materials with a variety of coatings current designs (Table 2) is still limited in their capability to extend patient lifetime beyond 6-12 months [2]. Metal stents alone fail due to ingrowth of cancerous tissue [76], whilst the addition of coatings to prevent such ingrowth results in the increased migration of the stent within the oesophagus $[30,31,54,55,80]$. This latter issue has subsequently led to perforation of the oesophageal muscle wall and in cases has resulted in patient morbidity [1, 32, 33, 38]. NiTiNOL stents present a unique selfexpanding capability for the prolonged patency of oesophageal strictures [56, 57], but more work is needed to optimise the corrosion resistance against acid reflux [1, 24]. A promising plasma treatment technique utilising $\mathrm{H}_{2}$ and $\mathrm{O}_{2}$ grows a nickel-free passive layer [60], reducing the risk of nickel-sensitisation of the peri-prosthetic tissue. Although palliation is designed to ease the distress of terminal conditions, extending the prognosis of patients offers a wide variety of design development opportunities for clinicians and materials researchers to advance the outlook of other cancer treatments for those same patients.

\section{Funding}

This research was supported by EPSRC Centre for Doctoral Training in Advanced Biomedical Materials grant reference number EP/S022201/1.

\section{Declarations}

Conflict of interest The authors declare that they have no conflict of interest.

Open Access This article is licensed under a Creative Commons Attribution 4.0 International License, which permits use, sharing, adaptation, distribution and reproduction in any medium or format, as long as you give appropriate credit to the original author(s) and the source, provide a link to the Creative Commons licence, and indicate if changes were made. The images or other third party material in this article are included in the article's Creative Commons licence, unless indicated otherwise in a credit line to the material. If material is not included in the article's Creative Commons licence and your intended use is not permitted by statutory regulation or exceeds the permitted use, you will need to obtain permission directly from the copyright holder. To view a copy of this licence, visit http://creativecommons.org/licen ses/by/4.0/.

\section{References}

[1] Black S, Edwards D, Smith G, Laasch H-U (2018) Gastrointestinal stents: materials and designs. Dig Dis Interv 02:003-010. https://doi.org/10.1055/s-0038-1639613

[2] Kaltsidis H, Mansoor W, Park JH et al (2018) Oesophageal stenting: status quo and future challenges. Br J Radiol. $\mathrm{h}$ ttps://doi.org/10.1259/bjr.20170935

[3] Bray F, Ferlay J, Soerjomataram I et al (2018) Global cancer statistics 2018: GLOBOCAN estimates of incidence and mortality worldwide for 36 cancers in 185 countries. CA Cancer J Clin. https://doi.org/10.3322/caac.21492 
[4] Homs MYV, Siersema PD (2012) Chapter 28: Endoscopic Palliation of Malignant Dysphagia and Esophageal Fistulas. In: Ginsberg GG, Gostout CJ, Kochman ML, Norton ID (Eds) Clinical gastrointestinal endoscopy, 2nd edn, pp 350-372. https://doi.org/10.1016/B978-1-4377-1529-3. 00028-2

[5] Dai Y, Li C, Xie Y et al (2014) Interventions for dysphagia in oesophageal cancer. Cochrane Database Syst Rev. http s://doi.org/10.1002/14651858.CD005048.pub4

[6] Tan BHL, Brammer K, Randhawa N et al (2015) Sarcopenia is associated with toxicity in patients undergoing neo-adjuvant chemotherapy for oesophago-gastric cancer. Eur J Surg Oncol 41:333-338. https://doi.org/10.1016/j.e jso.2014.11.040

[7] Berry MF (2014) Esophageal cancer: staging system and guidelines for staging and treatment. J Thorac Dis 6(Suppl 3):S289-S297. https://doi.org/10.3978/j.issn.2072-1439.20 14.03 .11

[8] Edge SB, Byrd DR, Compton CC, Fritz AG, Greene FL, Trotti A (2010) Lip and Oral Cavity. AJCC Cancer Staging Manual, 7th edn. Springer, Chicago, pp 33-34

[9] Rice TW, Rusch VW, Ishwaran H, Blackstone EH (2010) Cancer of the esophagus and esophagogastric junction. Cancer 116:3763-3773. https://doi.org/10.1002/cncr.25146

[10] Demeester TR (1997) Esophageal carcinoma: current controversies. Semin Surg Oncol 13:217-233

[11] Adler DG, Baron TH (2001) Endoscopic palliation of malignant dysphagia. Mayo Clin Proc 76:731-738. http s://doi.org/10.4065/76.7.731

[12] Weston A (2011) Stents in the proximal esophagus: tailoring the stent to the patient to achieve success. YMGE 73:1106-1108. https://doi.org/10.1016/j.gie.2011.02.016

[13] D'Etoilles L (1845) De Lavacherie De l'Oesophagotomie. Bruxelles

[14] Frimberger E (1983) Expanding spiral - a new type of prosthesis for the palliative treatment of malignant esophageal stenoses. Endoscopy 15:213-214. https://doi.org/ 10.1055/s-2007-1021511

[15] Irani S, Kozarek RA (2013) Self-Expandable Stents in the Gastrointestinal Tract. In: Kozarek R, Baron T, Song H-Y (eds) Self-expandable stents in the gastrointestinal tract. Springer, New York, NY, New York, NY

[16] Davids PHP, Groen AK, Rauws EAJ et al (1992) Randomised trial of self-expanding metal stents versus polyethylene stents for distal malignant biliary obstruction. Lancet 340:1488-1492. https://doi.org/10.1016/0140-6736 (92) $92752-2$

[17] De Palma GD, di Matteo E, Romano G et al (1996) Plastic prosthesis versus expandable metal stents for palliation of inoperable esophageal thoracic carcinoma: a controlled prospective study. Gastrointest Endosc 43:478-482. http s://doi.org/10.1016/S0016-5107(96)70290-0

[18] Bona D, Laface L, Bonavina L et al (2010) Covered nitinol stents for the treatment of esophageal strictures and leaks. World J Gastroenterol 16:2260-2264. https://doi.org/10.37 48/wjg.v16.i18.2260

[19] Whiteoak SR, Frost R, Loehry J et al (2012) PWE-036 What is the survival of patients with oesophageal cancer following palliative stenting? Gut 61:A311.2-A311. http s://doi.org/10.1136/gutjnl-2012-302514d.36

[20] van Boeckel PG, Siersema PD, Sturgess R et al (2010) A new partially covered metal stent for palliation of malignant dysphagia: a prospective follow-up study. Gastrointest Endosc 72:1269-1273. https://doi.org/10.1016/j.gie.2010.0 7.040

[21] Laasch H, Lee S, Moss JG (2004) The British society of interventional radiology ROST - registry of oesophageal stenting first report 2004, First Repo. Henley-on-Thames: The British Institute of Radiology

[22] Waddell T, Verheij M, Allum W et al (2013) Gastric cancer+: ESMO-ESSO-ESTRO clinical practice guidelines for diagnosis, treatment and follow-up. Ann Oncol. https://doi. org/10.1093/annonc/mdt344

[23] Bang YJ, Van Cutsem E, Feyereislova A et al (2010) Trastuzumab in combination with chemotherapy versus chemotherapy alone for treatment of HER2-positive advanced gastric or gastro-oesophageal junction cancer (ToGA): A phase 3, open-label, randomised controlled trial. Lancet 376:687-697. https://doi.org/10.1016/S0140-6736( 10)61121-X

[24] Lunt CR, Najaran P, Edwards DE et al (2018) The vanishing stent: repeated fracture and dissolution of nitinol gastric stents in a long term cancer survivor. Gastrointest Interv 7:88-90. https://doi.org/10.18528/gii170010

[25] Khara HS, Diehl DL, Gross SA (2014) Esophageal stent fracture: case report and review of the literature. World $\mathrm{J}$ Gastroenterol 20:2715-2720. https://doi.org/10.3748/wjg.v 20.i10.2715

[26] Phillips-Hughes DJ (2010) Oesophageal Stents | BSIR. h ttps://www.bsir.org/patients/oesophageal-stents/. Accessed 15 Oct 2021

[27] Chen H, Shen W, Liu K (2017) Radioactive self-expanding stents for palliative management of unresectable esophageal cancer: a systematic review and meta-analysis. Dis Esophagus Off J Int Soc Dis Esophagus. https://doi.org/10. 1093/DOTE/DOW010

[28] Singh P, Singh A, Singh A et al (2016) Long term outcome in patients with esophageal stenting for cancer esophagus our experience at a rural hospital of Punjab, India. J Clin 
Diagn Res. https://doi.org/10.7860/JCDR/2016/22950. 8994

[29] Mushi BP, Mwachiro MM, Buckle G et al (2021) Improving access to self-expanding metal stents for patients with esophageal cancer in Eastern Africa: a stepwise implementation strategy. JCO Global Oncol 7:118-126. h ttps://doi.org/10.1200/GO.20.00318

[30] Hindy P, Hong J, Lam-Tsai Y, Gress F (2012) A comprehensive review of esophageal stents. Clin Adv Hematol Oncol 10:526-534

[31] Martinez JC, Puc MM, Quiros RM (2011) Esophageal stenting in the setting of malignancy. ISRN Gastroenterol 2011:1-9. https://doi.org/10.5402/2011/719575

[32] Schembre D (2010) Advances in esophageal stenting: the evolution of fully covered stents for malignant and benign disease. Adv Ther 27:413-425. https://doi.org/10.1007/s1 2325-010-0042-5

[33] Kim KY, Tsauo J, Song H-Y et al (2017) Self-expandable metallic stent placement for the palliation of esophageal cancer. J Korean Med Sci 32:1062-1071. https://doi.org/10. 3346/jkms.2017.32.7.1062

[34] Park DH, Lee SS, Lee TH et al (2011) Anchoring flap versus flared end, fully covered self-expandable metal stents to prevent migration in patients with benign biliary strictures: a multicenter, prospective, comparative pilot study (with videos). Gastrointest Endosc 73:64-70. http s://doi.org/10.1016/j.gie.2010.09.039

[35] Hussain Z, Diamantopoulos A, Krokidis M, Katsanos K (2016) Double-layered covered stent for the treatment of malignant oesophageal obstructions: systematic review and meta-analysis. World J Gastroenterol 22:7841-7850. http s://doi.org/10.3748/wjg.v22.i34.7841

[36] Verschuur EML, Homs MYV, Steyerberg EW et al (2006) A new esophageal stent design (Niti-S stent) for the prevention of migration: a prospective study in 42 patients. Gastrointest Endosc. https://doi.org/10.1016/j.gie.2005.07. 051

[37] Vermeulen BD, Reijm AN, van der Bogt RD et al (2019) Sa1285 Though-the-scope placement of a new fully covered metal esophageal stent for palliation of malignant dysphagia: a prospective feasibility study. Gastrointest Endosc 89:205. https://doi.org/10.1016/j.gie.2019.03.175

[38] Cusumano A, Ruol A, Segalin A et al (1992) Push-through intubation: Effective palliation in 409 patients with cancer of the esophagus and cardia. Ann Thorac Surg 53:1010-1014. https://doi.org/10.1016/0003-4975(92)9037 6-F

[39] Mocanu A, Bârla R, Hoara P, Constantinoiu S (2015) Endoscopic palliation of advanced esophageal cancer. J Med Life 8:193-201
[40] García-Cano J (2008) Dilation of benign strictures in the esophagus and colon with the polyflex stent: a case series study. Dig Dis Sci 53:341-346. https://doi.org/10.1007/s1 0620-007-9864-7

[41] Costamagna G, Shah SK, Tringali A et al (2003) Prospective evaluation of a new self-expanding plastic stent for inoperable esophageal strictures. Surg Endosc Other Interv Tech 17:891-895. https://doi.org/10.1007/s00464-0 02-9098-x

[42] Langer FB, Wenzl E, Prager G et al (2005) Management of postoperative esophageal leaks with the polyflex self-expanding covered plastic stent. Ann Thorac Surg 79:398-403. https://doi.org/10.1016/j.athoracsur.2004.07. 006

[43] Holm AN, de la Mora Levy JG, Gostout CJ et al (2008) Self-expanding plastic stents in treatment of benign esophageal conditions. Gastrointest Endosc 67:20-25. https://d oi.org/10.1016/j.gie.2007.04.031

[44] Boston Scientific Corporation (2014) Polyflex Esophageal Stent

[45] Tokar JL, Banerjee S, Barth BA et al (2011) Drug-eluting/ biodegradable stents. Gastrointest Endosc 74:954-958. h ttps://doi.org/10.1016/j.gie.2011.07.028

[46] Sigounas D, Siddhi S, Plevris J (2016) Biodegradable esophageal stents in benign and malignant strictures - a single center experience. Endosc Int Open 04:E618-E623. https://doi.org/10.1055/s-0042-105433

[47] Pereira-Lima JC, Ramires RP, Zamin I et al (1999) Endoscopic dilation of benign esophageal strictures: Report on 1043 procedures. Am J Gastroenterol 94:1497-1501. http s://doi.org/10.1111/j.1572-0241.1999.01061.x

[48] ELLA-CS (2020) BD STENT

[49] Irani S, Kozarek RA (2013) History of GI Stenting: Rigid Prostheses in the Esophagus. Self-expandable stents in the gastrointestinal tract. Springer, New York, New York, NY

[50] May A, Hahn EG, Ell C (1996) Self-expanding metal stents for palliation of malignant obstruction in the upper gastrointestinal tract: comparative assessment of three stent types implemented in 96 implantations. J Clin Gastroenterol 22:261-266. https://doi.org/10.1097/00004836-19960 6000-00004

[51] Laasch HU, Marriott A, Wilbraham L et al (2002) Effectiveness of open versus antireflux stents for palliation of distal esophageal carcinoma and prevention of symptomatic gastroesophageal reflux. Radiology 225:359-365. https://d oi.org/10.1148/radiol.2252011763

[52] Ell C, May A, Hahn EG (1995) Gianturco-Z Stents in the palliative treatment of malignant esophageal obstruction and esophagotracheal fistulas. Endoscopy 27:495-500. h ttps://doi.org/10.1055/s-2007-1005754 
[53] McDevitt JL, Goldman DT, Bundy JJ et al (2020) Gianturco z-stent placement for the treatment of chronic central venous occlusive disease: implantation of 208 stents in 137 symptomatic patients. Diagnostic Interv Radiol 27:72-78. h ttps://doi.org/10.5152/dir.2020.19282

[54] Otsuka K, Ren X (2005) Physical metallurgy of Ti-Nibased shape memory alloys. Prog Mater Sci 50:511-678

[55] Christian JW (2002) Chapter 26: Shape Memory Alloys. In: The Theory of Transformations in Metal and Alloys. Pergamom, pp 1102-1113

[56] Solomon JA, Stavropolous SW (2010) Equipment, terms, and techniques in interventional radiology. In: Radiology Secrets Plus: Third Edition. Mosby, pp 217-222

[57] Pandit A, Planell J, Navarro M (2013) Titanium and Nitinol (NiTi). In: Biomaterials Science: An Introduction to Materials: Third Edition. Elsevier Inc., pp 120-124

[58] Lemons JE, Misch-Dietsh F, McCracken MS (2014) Biomaterials for Dental Implants. In: Dental Implant Prosthetics. Elsevier Inc., pp 66-94

[59] Brochu ABW, Craig SL, Reichert WM (2011) Self-healing biomaterials. J Biomed Mater Res - Part A 96A:492-506. h ttps://doi.org/10.1002/jbm.a.32987

[60] Jenko M, Godec M, Kocijan A et al (2019) A new route to biocompatible Nitinol based on a rapid treatment with $\mathrm{H} 2 /$ O2 gaseous plasma. Appl Surf Sci 473:976-984. https://d oi.org/10.1016/j.apsusc.2018.12.140

[61] Thyssen JP, Johansen JD, Menné T et al (2010) Hypersensitivity reactions from metallic implants: a future challenge that needs to be addressed. $\mathrm{Br} \mathrm{J}$ Dermatol 162:235-236. https://doi.org/10.1111/j.1365-2133.2009.09 526.x

[62] Biesiekierski A, Wang J, Abdel-Hady Gepreel M, Wen C (2012) A new look at biomedical Ti-based shape memory alloys. Acta Biomater 8:1661-1669. https://doi.org/10.101 6/j.actbio.2012.01.018

[63] Köster R, Vieluf D, Kiehn M et al (2000) Nickel and molybdenum contact allergies in patients with coronary instent restenosis. Lancet 356:1895-1897. https://doi.org/10. 1016/S0140-6736(00)03262-1

[64] Mönkemüller K, Zimmermann L (2009) Self-Expanding Metallic Stents for the Palliation of Malignant Esophageal Obstruction. In: Mönkemüller K, Wilcox C, Muñoz-Navas $\mathrm{M}$ (eds) Interventional and Therapeutic Gastrointestinal Endoscopy. KARGER, Basel, pp 106-114

[65] Goldin E, Beyar M, Safra T et al (1994) A new self-expandable, nickel-titanium coil stent for esophageal obstruction: a preliminary report. Gastrointest Endosc 40:64-68. https://doi.org/10.1016/S0016-5107(94)70012-5

[66] Naso P, Bonanno G, Aprile G et al (2001) EsophaCoil for palliation of dysphagia in unresectable oesophageal carcinoma: short- and long-term results. Dig Liver Dis 33:653-658. https://doi.org/10.1016/S1590-8658(01)8004 $0-2$

[67] Maetani I, Nambu T, Omuta S et al (2010) Treating bilioduodenal obstruction: combining new endoscopic technique with $6 \mathrm{Fr}$ stent introducer. World J Gastroenterol 16:2828-2831. https://doi.org/10.3748/wjg.v16.i22.2828

[68] Yoshida H, Tajiri T, Mamada Y et al (2004) Fracture of a biliary expandable metallic stent. Gastrointest Endosc 60:655-658. https://doi.org/10.1016/S0016-5107(04)0188 4-X

[69] Ali MN, Busfield JJC, Rehman IU (2014) Auxetic oesophageal stents: structure and mechanical properties. J Mater Sci Mater Med 25:527-553. https://doi.org/10.1007/s1085 6-013-5067-2

[70] Grima JN, Jackson R, Alderson A, Evans KE (2000) Do zeolites have negative poisson's ratios? Adv Mater 12:1912-1918. https://doi.org/10.1002/1521-4095(200012) 12:24\%3c1912::AID-ADMA1912\%3e3.0.CO;2-7

[71] Laasch H-U, Edwards DW, Song H-Y (2016) Enteral stent construction: current principles. Gastrointest Interv 5:85-89. https://doi.org/10.18528/gii160009

[72] Kang S-G (2010) Gastrointestinal stent update. Gut Liver 4:S19. https://doi.org/10.5009/gnl.2010.4.S1.S19

[73] McHugo V (2014) Braided helical wire stent - US Patent 8, 875,372. Google Patents

[74] Kang Y (2019) A review of self-expanding esophageal stents for the palliation therapy of inoperable esophageal malignancies. Biomed Res Int 2019:1-11. https://doi.org/ 10.1155/2019/9265017

[75] Yakoub D, Ramy AE, Ae F et al (2008) Evidence-based choice of esophageal stent for the palliative management of malignant dysphagia. World J Surg 32:1996-2009. https://d oi.org/10.1007/s00268-008-9654-1

[76] Ramakrishnaiah VPN, Malage S, Sreenath GS et al (2016) Palliation of dysphagia in carcinoma esophagus. Clin Med Insights Gastroenterol 9:11-23

[77] Meike C, Hirdes AM, Vleggaar FP, de Beule M et al (2013) In vitro evaluation of the radial and axial force of selfexpanding esophageal stents. Endoscopy. https://doi.org/10. 1055/s-0033-1344985

[78] Eickhoff A, Knoll M, Jakobs R et al (2005) Self-expanding metal stents versus plastic prostheses in the palliation of malignant dysphagia: Long-term outcome of 153 consecutive patients. J Clin Gastroenterol 39:877-885. https://doi. org/10.1097/01.mcg.0000180631.61819.4a

[79] Orive-Calzada A, Álvarez-Rubio M, Romero-Izquierdo S et al (2009) Severe epithelial hyperplasia as a complication of a novel biodegradable stent. Endoscopy 41:E137-E138. https://doi.org/10.1055/s-0029-1214634 
[80] Ramirez FC, Dennert B, Zierer ST, Sanowski RA (1997) Esophageal self-expandable metallic stents-indications, practice, techniques, and complications: Results of a national survey. Gastrointest Endosc 45:360-364. https://d oi.org/10.1016/S0016-5107(97)70144-5

[81] Boston Scientific Corporation (2014) WallFlex

[82] Franca DCC, de Castro AL, Soubhia AMP et al (2013) Evaluation of the biocompatibility of silicone gel implantshistomorphometric study. Acta Inform Medica 21:93-97. h ttps://doi.org/10.5455/aim.2013.21.93-97

[83] Sardar VB, Rajhans NR, Pathak A, Prabhu T (2016) Development in silicone material for biomedical applications. In: 14th International Conference on Humanizing Work and Work Environment HWWE-2016

[84] Kim HB, Baik KY, Moon MH, Sung CK (2016) Enhanced Corrosion Resistance of Silicone-Coated Stents by Plasma Treatment. In: 5th International Science Congress \& Exhibition. pp 857-860

[85] Maitz MF (2015) Applications of synthetic polymers in clinical medicine. Biosurface and Biotribology 1:161-176. https://doi.org/10.1016/j.bsbt.2015.08.002

[86] Park JS, Jeong S, Lee DH (2015) Recent advances in gastrointestinal stent development. Clin Endosc 48:209-215. https://doi.org/10.5946/ce.2015.48.3.209

[87] Mikhailov IV, Sidorchuk SV, Lavrusenko SR (2002) Polytetrafluoroethylene in medicine. Int Polym Sci Technol 29:38-41

[88] Cardoso VF, Correia DM, Ribeiro C et al (2018) Fluorinated polymers as smart materials for advanced biomedical applications. Polymers (Basel). https://doi.org/10.3390/ polym 10020161

[89] Ebnesajjad S (2017) Medical and Surgical Applications of Expanded PTFE. In: Expanded PTFE Applications Handbook. Elsevier, pp 193-211

[90] Ebnesajjad S (2017) Properties, Characteristics, and Applications of Expanded PTFE (ePTFE) Products. In: Expanded PTFE Applications Handbook. Elsevier, pp 163-170

[91] Vera ML, Rosenberger MR, Schvezov CE, Ares AE (2015) Fabrication of $\mathrm{TiO} 2$ crystalline coatings by combining Ti$6 \mathrm{Al}-4 \mathrm{~V}$ anodic oxidation and heat treatments. Int $\mathrm{J}$ Biomater. https://doi.org/10.1155/2015/395657

[92] Regonini D, Jaroenworaluck A, Stevens R, Bowen CR (2010) Effect of heat treatment on the properties and structure of $\mathrm{TiO} 2$ nanotubes: phase composition and chemical composition. Surface Interface Anal. https://doi. org/10.1002/sia.3183

[93] Lu T, Qiao Y, Liu X (2012) Surface modification of biomaterials using plasma immersion ion implantation and deposition. Interface Focus. https://doi.org/10.1098/rsfs.20 12.0003

[94] Wang G, Li J, Lv K et al (2016) Surface thermal oxidation on titanium implants to enhance osteogenic activity and in vivo osseointegration. Nat Publ Gr. https://doi.org/10. 1038/srep31769

[95] Cigada A, Cabrini M, Pedeferri P (1992) Increasing of the corrosion resistance of the Ti6Al4V alloy by high thickness anodic oxidation. J Mater Sci Mater Med 3:408-412. h ttps://doi.org/10.1007/BF00701236

[96] Vera ML, Alterach MÁ, Rosenberger MR et al (2014) Characterization of $\mathrm{TiO}_{2}$ nanofilms obtained by sol-gel and anodic oxidation. Nanomater Nanotechnol 4:10. https://doi. org/10.5772/58522

[97] Armitage DA, Grant DM (2003) Characterisation of surface-modified nickel titanium alloys. Mater Sci Eng A 349:89-97. https://doi.org/10.1016/S0921-5093(02)008183

[98] Liu X, Chu PK, Ding C (2004) Surface modification of titanium, titanium alloys, and related materials for biomedical applications. Mater Sci Eng R Reports 47:49-121. https://doi.org/10.1016/j.mser.2004.11.001

[99] Anders A (1997) Metal plasma immersion ion implantation and deposition: a review. Surf Coatings Technol. https://d oi.org/10.1016/S0257-8972(97)00037-6

[100] Pohl M, Glogowski T, Kühn S et al (2008) Formation of titanium oxide coatings on NiTi shape memory alloys by selective oxidation. Mater Sci Eng A 481:123-126. http s://doi.org/10.1016/j.msea.2007.02.151

[101] Schvezov CE, Alterach MA, Vera ML et al (2010) Characteristics of hemocompatible $\mathrm{TiO} 2$ nano-films produced by the sol-gel and anodic oxidation techniques. J Miner Met Mater Soc 62:84-87. https://doi.org/10.1007/s11837-0100094-7

[102] Velten D, Biehl V, Aubertin F et al (2002) Preparation of $\mathrm{TiO} 2$ layers on cp-Ti and Ti6Al4V by thermal and anodic oxidation and by sol-gel coating techniques and their characterization. J Biomed Mater Res 59:18-28. https://doi. org/10.1002/jbm. 1212

[103] Nebol'sin VA, Spiridonov BA, Dunaev AI, Bogdanovich EV (2017) Preparation of nanoporous titanium oxide films by electrochemical anodic oxidation. Inorg Mater 53:595-601. https://doi.org/10.1134/S0020168517060139

[104] Mabiala Masiala T (2016) Influence of $\mathrm{pH}$ preparation on the photo-response of electrodeposited titanium dioxide (TiO2) thin films. Int J Mater Sci Appl 5:207. https://doi. org/10.11648/j.ijmsa.20160505.15

[105] Bektaş H, Gürbulak B, Düzköylü Y et al (2017) Clinical outcomes of upper gastrointestinal stents and review of 
current literature. J Soc Laparoendosc Surg. https://doi.org/ 10.4293/JSLS.2017.00058

[106] Tutuian R, Castell DO (2006) Gastroesophageal reflux monitoring: $\mathrm{pH}$ and impedance. In: GI Motility online. Nature Publishing Group

[107] ATSM International (2015) ASTM F2129 - 15 Standard Test Method for Conducting Cyclic Potentiodynamic Polarization Measurements to Determine the Corrosion Susceptibility of Small Implant Devices. www.astm.org. Accessed 22 Nov 2019

[108] Siersema PD (2008) Treatment options for esophageal strictures. Nat Clin Pract Gastroenterol Hepatol 5:142-152

[109] Mangiavillano B, Manes G, Baron TH et al (2014) The use of double lasso, fully covered self-expandable metal stents with new "anchoring flap" system in the treatment of benign biliary diseases. Dig Dis Sci 59:2308-2313. http s://doi.org/10.1007/s10620-014-3158-7

[110] Lowe AS, Sheridan MB (2004) Esophageal stenting. Semin Intervent Radiol 21:157-166

[111] Tomaselli F, Maier A, Sankin O, et al (2004) Ultraflex stent-benefits and risks in ultimate palliation of advanced, malignant stenosis in the esophagus. Hepatogastroenterology 51(58):1021-1026

[112] Laasch HU (2013) Current designs of self-expanding stents. Self-expandable stents in the gastrointestinal tract. Springer, New York

[113] Philbin Ch. A., Stivaros S. M., Mullan D., Laasch H. U. et al. (2013) Oesophageal stents with anti-migration design: Getting a grip on stent displacement. In: Presentation at British Society of Interventional Radiology Annual Meeting. Manchester

[114] ELLA-CS (2021) HV Stent Plus

[115] Taewoong Medical Co. (2019) Double Esophageal Stent

[116] Yang K, Ling C, Yuan $T$ et al (2016) Polymeric biodegradable stent insertion in the esophagus. Polymers (Basel) 8(5):158. https://doi.org/10.3390/polym8050158

[117] Fry SW, Fleischer DE (1997) Management of a refractory benign esophageal stricture with a new biodegradable stent. Gastrointest Endosc 45:179-182. https://doi.org/10.1016/S 0016-5107(97)70244-X

[118] Goldin E, Fiorini A, Ratan Y et al (1996) A new biodegradable and self-expandable stent for benign esophageal strictures. Gastrointest Endosc 43:294. https://doi. org/10.1016/S0016-5107(96)80017-4

[119] Liu J, Shang L, Liu J, Qin C (2016) A novel biodegradable esophageal stent: Results from mechanical and animal experiments. Am J Transl Res 8:1108-1114

[120] Neumann IA, Flores-Sahagun THS, Ribeiro AM (2017) Biodegradable poly (L-lactic acid) (PLLA) and PLLA-3arm blend membranes: the use of PLLA-3-arm as a plasticizer. Polym Test 60:84-93. https://doi.org/10.1016/j. polymertesting.2017.03.013

[121] Tanaka T, Takahashi M, Nitta N et al (2006) Newly developed biodegradable stents for benign gastrointestinal tract stenoses: a preliminary clinical trial. Digestion 74:199-205. https://doi.org/10.1159/000100504

[122] Kariduraganavar MY, Kittur AA, Kamble RR (2014) Polymer Synthesis and Processing. In: Natural and Synthetic Biomedical Polymers. Elsevier Inc., pp 1-31

[123] Pauli EM, Schomisch SJ, Furlan JP et al (2012) Biodegradable esophageal stent placement does not prevent high-grade stricture formation after circumferential mucosal resection in a porcine model. Surg Endosc 26:3500-3508. h ttps://doi.org/10.1007/s00464-012-2373-6

[124] Kwon CI, Ko KH, Hahm KB, Kang DH (2013) Functional self-expandable metal stents in biliary obstruction. Clin Endosc 46:515-521. https://doi.org/10.5946/ce.2013.46.5. 515

[125] Spuentrup E, Ruebben A, Mahnken A et al (2005) Artifactfree coronary magnetic resonance angiography and coronary vessel wall imaging in the presence of a new, metallic, coronary magnetic resonance imaging stent. Circulation 111:1019-1026. https://doi.org/10.1161/01.CIR.00001564 $62.97532 .8 \mathrm{~F}$

[126] Kalinowski M, Alfke H, Kleb B et al (2002) Paclitaxel inhibits proliferation of cell lines responsible for metal stent obstruction: possible topical application in malignant bile duct obstructions. Invest Radiol 37:399-404. https://doi.or g/10.1097/00004424-200207000-00007

[127] Zhang Y, Ma L, Huang J et al (2017) The effect of paclitaxel-eluting covered metal stents versus covered metal stents in a rabbit esophageal squamous carcinoma model. PLoS ONE. https://doi.org/10.1371/journal.pone.0173262

[128] Lee JW, Yang SG, Na K (2012) Gemcitabine-releasing polymeric films for covered self-expandable metallic stent in treatment of gastrointestinal cancer. Int $\mathrm{J}$ Pharm 427:276-283. https://doi.org/10.1016/j.ijpharm.2012.02. 016

[129] Chung MJ, Kim H, Kim KS et al (2012) Safety evaluation of self-expanding metallic biliary stents eluting gemcitabine in a porcine model. J Gastroenterol Hepatol 27:261-267. h ttps://doi.org/10.1111/j.1440-1746.2011.06866.x

[130] Liu J, Wang Z, Wu K et al (2015) Paclitaxel or 5-fluorouracil/esophageal stent combinations as a novel approach for the treatment of esophageal cancer. Biomaterials 53:592-599. https://doi.org/10.1016/j.biomaterials.2015.03 .009

[131] Shaikh M, Choudhury NR, Knott R, Garg S (2015) Engineering stent based delivery system for esophageal cancer 
using docetaxel. Mol Pharm 12:2305-2317. https://doi.org/ $10.1021 / \mathrm{mp} 500851 \mathrm{u}$

[132] Zhu Y-Q, Cui W-G, Cheng Y-S et al (2013) Evaluation of biodegradable paclitaxel-eluting nanofibre-covered metal stents for the treatment of benign cardia stricture in an experimental model. Br J Surg 100:784-793. https://doi. org/10.1002/bjs.9106

[133] Gianfaldoni S, Gianfaldoni R, Wollina U et al (2017) An overview on radiotherapy: from its history to its current applications in dermatology. Open Access Maced J Med Sci 5:521-525. https://doi.org/10.3889/oamjms.2017.122

[134] Kwon SJ (2005) Management of side effects of 5-FU based chemotherapy. Korean J Clin Oncol 1:51-58

[135] Lei L, Liu X, Guo S et al (2010) 5-Fluorouracil-loaded multilayered films for drug controlled releasing stent application: drug release, microstructure, and ex vivo permeation behaviors. J Control Release 146:45-53. https://d oi.org/10.1016/j.jconrel.2010.05.017

[136] Homs MYV, Steyerberg EW, Eijkenboom WMH et al (2004) Single-dose brachytherapy versus metal stent placement for the palliation of dysphagia from oesophageal cancer: multicentre randomised trial. Lancet 364:1497-1504. https://doi.org/10.1016/S0140-6736(04)1 7272-3

[137] The Christie NFT What is brachytherapy? https:/www.ch ristie.nhs.uk/patients-and-visitors/your-treatment-and-care/t reatments/other-treatments/brachytherapy/what-is-brachyth erapy/. Accessed 21 Nov 2019

[138] Guo J-H, Teng G-J, Zhu G-Y et al (2007) Self-expandable stent loaded with $125 \mathrm{I}$ seeds: feasibility and safety in a rabbit model. Eur J Radiol 61:356-361. https://doi.org/10. 1016/j.ejrad.2006.10.003

[139] Guo JH, Teng GJ, Zhu GY et al (2008) Self-expandable esophageal stent loaded with $125 \mathrm{I}$ seeds: initial experience in patients with advanced esophageal cancer. Radiology 247:574-581. https://doi.org/10.1148/radiol.2472070999

[140] Liu N, Liu S, Xiang C et al (2014) Radioactive self-expanding stents give superior palliation in patients with unresectable cancer of the esophagus but should be used with caution if they have had prior radiotherapy. Ann Thorac Surg 98:521-526. https://doi.org/10.1016/j.athorac sur.2014.04.012

[141] Herskovic AM, Rivard M, Rothstein RI et al (2017) Radiation esophageal stent. J Clin Oncol 35:e15514e15514. https://doi.org/10.1200/jco.2017.35.15_suppl.e 15514

[142] Davies RP, Kew J, Byrne PD (2000) Treatment of poststent gastroesophageal reflux by anti-reflux Z-stent. Cardiovasc Intervent Radiol 23:487-489. https://doi.org/10.10 07/s002700010113

[143] Do YS, Choo SW, Suh SW et al (2001) Malignant esophagogastric junction obstruction: palliative treatment with an antireflux valve stent. J Vasc Interv Radiol 12:647-651. h ttps://doi.org/10.1016/s1051-0443(07)61493-6

[144] Homs MYV, Wahab PJ, Kuipers EJ et al (2004) Esophageal stents with antireflux valve for tumors of the distal esophagus and gastric cardia: a randomized trial. Gastrointest Endosc 60:695-702. https://doi.org/10.1016/s0016-5107(0 4)02047-4

[145] Coron E, David G, Lecleire S et al (2016) Antireflux versus conventional self-expanding metallic Stents (SEMS) for distal esophageal cancer: results of a multicenter randomized trial. Endosc Int Open 04:E730-E736. https://doi.org/ $10.1055 / \mathrm{s}-0042-106960$

Publisher's Note Springer Nature remains neutral with regard to jurisdictional claims in published maps and institutional affiliations. 